Aus dem pathologischen Institut der Universität $z u$ Breslau. Direktor: Geheimrat Ponfick.

\title{
Die Beziehungen der Hyperemesis gravidarum zur akuten gelben Leberatrophie und sonstigen Sektionsbefunden.
}

\author{
Von
}

Privatdozent Dr. Paul Heinrichsdorff.

Ueber das Wesen der Hyperemesis gravidarum ist bis heute eine Einigung unter den Autoren nieht erzielt worden, nur soviel ist sicher, dass die meisten Fälle dieser seltenen Erkrankung in Heilung übergehen. Die eigentümlichen Umstände, unter denen diese erfolgt, haben seit Ahlfeld und Kaltenbach die Erklärung gefunden, dass die reflektorische und zentrale Erregbarkeit des Brechzentrums bei diesen Graviden hochgradig gesteigert sei, und dass durch Einflussnahme auf die Orte der primären Erregung oder auf das Seelenleben dieser Zustand behoben werden kann. Auch diejenigen, welche noch andere Erklärungen der Hyperemesis zulassen, haben die Richtigkeit der soeben gegebenen für die meisten Fälle anerkannt. Nun ist aber seit langem bekannt, dass nicht alle Patienten mit unstillbarem Erbrechen genesen, dass vielmehr ein Teil von ihnen meistens unter Auftreten von Albuminurie, Ikterus und Koma zugrunde geht. Dieses ist auch der. Grund dafür, dass man seit Dubois allseitig die Berechtigung der künstlichen Frühgeburt für einzelne schwere Fälle von Hyperemesis anerkannt hat, obwohl sich manche Praktiker von grosser Erfahrung rühmen, niemals zu einem solchen Schritte gezwungen gewesen zu sein. Die Tatsache des tödlichen Ausgangs mancher Fälle ist vom Standpunkte der Ahlfeld-Kaltenbach'schen Theorie schwer zu erklären, da eine im Grunde genommen doch rein funktionelle Alteration des Nervensystems, wie sie von diesen Autoren angenommen wird, nach der Ansicht der Meisten so ernste Folgen nicht zeitigen kann. So ist denn die toxische Theorie 
aufgekommen. Hiernach sollen Giftstoffe, deren Entstehung durch die Gravidität bedingt ist, zum unstillbaren Erbrechen Veranlassung geben, wie das für zwei andere in der Gravidität vorkommende Affektionen, nämlich die Eklampsie und die akute gelbe Leberatrophie wohl jetzt allgemein anerkannt ist. Man stützte sich bei dem Bestreben, diese toxische Theorie auch auf die Hyperemesis auszudehnen, einerseits auf klinische Untersuchungen, die eine bemerkenswerte Abweichung vom normalen N-Stoffwechsel ergaben, andererseits auf bei der Sektion erhobene anatomische Befunde. Insbesondere war es Williams, der auf Grund seiner sehr exakten Untersuchungen die Hyperemesis in drei Arten einteilte, und eine reflektorische, eine neurotische und eine toxische Form unterschied. Die letzteren seien durch Sektionsbefunde, die denen der akuten Leberatrophie glichen, ausgezeichnet. Die pathologisch-anatomischen Veränderungen sprechen ja zweifellos für das Bestehen einer Toxämie und erklären so auch in befriedigender Weise den Eintritt des Todes. Darum habe ich mich in einer früheren Arbeit ${ }^{1}$ ) für die toxische Aetiologie dieser Formen ausgesprochen.

Gegen die Williams'sche Auffassung hat nun Winter ${ }^{2}$ ) einen sehr beachtenswerten Einwand erhoben. Für ihn ist es vom klinischen Standpunkte aus nicht gerechtfertigt, eine solche Dreiteilung der Hyperemesis vorzunehmen, vielmehr weise ihr gleichartiger Beginn und Verlauf auch auf eine einheitliche Natur dieser Affektion hin. Da nun einerseits die neurotische Aetiologie durch vielfache Erfahrung sichergestellt ist, andererseits aber auch der toxische Charakter der bei der Sektion beobachteten anatomischen Anomalien nicht bezweifelt werden kann, so nimmt er an, dass jede Hyperemesis als Reflexneurose beginne, und dass nur unter besonders ungünstigen Umständen auf dem Boden derselben eine Intoxikation zustande käme, welche die eigentümlichen Organveränderungen zur Folge habe.

Es ist nicht zu verkennen, dass diese Auffassung etwas ungemein Bestechendes hat. Die praktische Unmöglichkeit, die schweren, letal endenden Formen vorher zu erkennen, so rechtzeitig, dass man durch künstliche Entbindung den Tod verhüten kann, wäre dadurch plausibel gemacht, dass die Hyperemesiserkrankungen in Wirklichkeit alle von der gleichen, zunächst

1) Die anatomischen Leberveränderungen in der Schwangerschaft. Zeitschr. f. Geburtsh, u. Gyn. Bd. 70.

2) Zentralbl. f. Gyn. 1907. Nr. 48. 
also harmlosen Natur seien. Bei der hochgradigen Schwächung: des Organismus infolge des unstillbaren Erbrechens wäre der Eintritt von Intoxikationen durchaus verständlich, zumal seit längerer Zeit mit deren Vorkommen in der Gravidität - auch ohne prädisponierende Momente - gerechnet wird. Im klinischen Bilde zeigt sich oft schon eine deutliche Grenze zwischen einfacher Hyperemesis und dem schweren toxischen Allgemeinzustande; dieser letztere wurde nach der herkömmlichen Ansicht als die dritte und letzte Phase des ganzen Prozesses betrachtet.

Als ich nun durch eine eigene Beobachtung tödlich endender Hyperemesis gravidarum von neuem auf diesen Gegenstand hingelenkt wurde, habe ich die anatomischen Untersuchungen in erweitertem Umfange von diesem neuen Gesichtspunkt aus aufgenommen. Es schwebte mir als Ziel vor, anatomische Grundlagen für die eine oder die andere Auffassung zu finden. Die Frage, auf die es dabei ankommt, ist folgende: Welches Alter haben die Sektionsbefunde, speziell die in der Leber? Gehen diese in ihren Anfängen bis auf die Zeit des klinischen Eintritts der Hyperemesis zurück, so ist füglich an der Richtigkeit der Williams'schen Hypothese, dass damals schon Giftstoffe die Veranlassung zur Erkrankung gaben, nicht zu zweifeln. Sind die Veränderungen aber jüngeren Datums als der Hyperemesis entspricht, so würde die Winter'sche Auffassung von dem erst späteren Eintritt der Intoxikation sich mit den anatomischen Befunden decken, und ihr daher vom Anatomen auch der Vorzug gegeben werden müssen vor jener anderen, für die wir keine solchen anatomischen Beweise in Händen haben.

So untersuchte ich denn ausser dem von mir selbst noch beizubringenden Fall auch alle anderen gleichen und ähnlichen, soweit sie mir zugänglich waren. Und zwar vornehmlich diejenigen, welche die Befunde der akuten gelben Leberatrophie dargeboten haben, da wir hier über die Veränderungen, welche durch frische oder ältere Erkrankungen bedingt sind, gut unterrichtet sind. Bei der Besprechung der Fälle folge ich Williams, der eine ausgezeichnete Abhandlung über diesen Gegenstand: „Pernicious vomiting of pregnancy" im Bulletin of the Johns Hopkins Hospital 1906 veröffentlicht hat. Es wird für unseren Zweck nötig sein, das klinische Bild dem anatomischen in jedem Falle gegenüberzustellen, wobei wir zugleich einen Einblick in die wahre Häufigkeit der als gelbe Leberatrophie erscheinenden Fälle von Hyperemesis gewinnen. 
Den Herren Professoren Williams, Marchand, Ahlfeld, Küstoer, Strümpell, Minkowsky, Pertik und meinem hochverehrten Chef Herrn Geheimrat Ponfick bin ich für Ueberlassung von Material - Abhandlungen, Krankengeschichten, Sektionsprotokollen und Präparaten - zu grossem Dank verpflichtet.

Williams beginnt mit einem Fall von Duncan: "Clinical lecture on hepatic diseases in gynaecology and obstetrics". The medical Times and Gazette London. 1879. p. 57.

E. C., 34 jährige Frau, seit etwa $1 \mathrm{Jahr}$ verheiratet; 3 Monate nach der Heirat hatte sie eine Fehlgeburt, wie angenommen wird im 2. Monat der Schwangerschaft; damals war ihr Zustand ähnlich dem, der jetzt bei ihrer Einlieferung ins Krankenhaus besteht, nur soll der Ikterus stärker gewesen sein. Ihre jetzige Krankheit begann etwa 5 Wochen vor ihrer Einlieferung (2. Dezember) mit Brechen und Kopfschmerz, von dem ersteres ununterbrochen seitdem bestanden hat. Sie hat 3 oder 4 Wochen das Bett gehütet, der Ikterus soll allmählich stärker geworden sein (hat also auch schon früher bestanden! Der Verf.). Sie hat Delirien gehabt, in denen sie unruhig hin und her wanderte, besonders nachts. Bei ihrer Aufnahme ist sie auch in so einem $\mathrm{Zu}-$ stande der Benommenheit und gibt an, keine Schmerzen zu haben. Es besteht allgemeiner, wenn auch leichter Ikterus. Zunge feucht, nicht belegt, Atem übelriechend, kein Jucken, kein Gelbsehen, Puls 108, Resp. 12, Temp. 37. Dämpfung über der Symphyse, Leib etwas gespannt, genaue Vaginalexploration nicht möglich. Leber und Milzdämpfung normal. Urin dunkel verfärbt, enthält Gallenfarbstoff, spezifisches Gewicht 1012, trübe Beschaffenheit, saure Reaktion, eiweisshaltig, enthält epitheliale Zylinder und rote Blutkörperchen. Obwohl Pat. nur Milch und Zwieback nimmt, bricht sie alles aus.

4. XII. Boraxwaschungen für den Mund. Durch salinische Abführungsmittel wird für Stuhl gesorgt. 5. XII. gelegentlich Singultus. 7. XII. Kopfschmerz. 8. XII. gut geschlafen, nachdem sie etwas Chloral genommen hatte. 9. XII. rektale Ernährung. 10. XII. Gelbsucht geringer, fühlt sich angeblich besser, Temp. 36,3, Puls 86. Am 11. XII. Urin etwa $600 \mathrm{~g}$ innerhalb von 24 Stunden, enthält Albumen. Singultus. Am 18. XII. Puls 128, Resp. 18, Temp. 36. 19. XII. Zunge belegt, Pat. ist mehr benommen und unruhig, bricht Nahrung und Galle, nur Spuren von Albumen im Urin, welche Leuzinkristalle enthalten, Harnstoffmenge $16 \mathrm{~g}$ innerhalb 24 Stunden. 21. XII. Leberdämpfung leicht vermindert, Pat. ist wenigér gelb. Jetzt wird zum künstlichen Abort geschritten, indem Gazestreifen in die Cervix geführt werden, diese werden nach 16 Stunden entfernt und am 24. XII. die Prozedur wiederholt. Am Nachmittag dieses Tages Exitus.

Sektion 48 Stunden post mortem ergibt bezüglich der

Leber: Klein, Gewicht $965 \mathrm{~g}$, sehr weich und welk anzufühlen, Oberfläche teils grün, besonders an den Kanten, teils braun, keine besonders starke Blutfülle, die Gallenblase enthält normal aussehende Galle. Beim Durchschneiden hat man das Gefühl des Luftgehalts, Farbe des Durchschnitts gleichmässig grünbraun, keine Spur von Läppchenzeichnung. Die ganze Leber ist hochgradio gashaltig, dabei aber nicht 
faul, gleicht beim Schneiden einem durch Kohlensäure stark aufgelockerten Brot.

Milz: Sehr dunkel, ebenfalls Iufthaltig.

Nieren: Weich, mit grossen Luftblasen unter der Kapsel und kleinen im Innern des Organs. Zeichnung verwischt. Grenze von Rinde und Mark stark hyperämisch.

Uterus: Enthält membranöse Fetzen und Luft, ferner einen stark zersetzten Fötus von 6 Wochen, Plazenta adhärent, misst 2 Zoll im Durchmesser.

Darminhalt: Gallig verfärbt.

Magen: Hyperämisch, zeigt in der Wand zahlreiche Gasblasen, auch die linke Vena iliaca communis enthält Luft ausser flüssigem Blut.

Wie man sieht, handelt es sich um eine akute gelbe Leberatrophie, allerdings ist der Fall nicht rein, da eine Infektion mit gasbildenden Bakterien hinzugetreten ist. Eine mikroskopische Untersuchung ist leider versäumt worden, aber sie hätte unter solchen Umständen wohl auch wenig erkennen lassen. Es fragt sich nun, ob hier überhaupt eine Hyperemesis gravidarum oder eine akute gelbe Leberatrophie rorgelegen habe. Duncan selbst nimmt das letztere an, und ich glaube, man muss sich ihm ohne weiteres anschliessen. Die Krankheit beginnt mit Erbrechen, Kopfschmerzen, Ikterus, es kommen bald Benommenheit, Unruhe, Deiirien hinzu, ferner eine ausgesprochene Nephritis, und dieser Zustand hält wochenlang an. Eine Hyperemesis lässt während der längsten Dauer ihres Verlaufes fast alle diese Zeichen vermissen. Das ist keine toxische Form der Hyperemesis, das ist eine akute gelbe Leberatrophie. Das Erbrechen ist hier lediglich eines der vielen Symptome, aber nicht wie bei der Hyperemesis das einzige. Dieser Fall scheidet somit aus der Betrachtung aus.

Williams führt dann weiter einen Fall an von Roughton: "Pernicious vomiting of pregnancy". Lancet 1885 . II. 425/26. Auch diese Beobachtung kann unsere Erkenntnis nicht fördern, da die Krankheit nach künstlicher Entbindung heilte und somit die Diagnose der akuten gelben Leberatrophie nicht zweifellos feststeht.

Ein dritter Fall wurde von Hirschberg veröffentlicht: „Drei Fälle von akuter gelber Leberatrophie." I.-D. Dorpat 1886.

Frau G., 25 Jahre alt, früher nie krank, seit 11/2 Jahren verheiratet, hat im Dezember 1884 abortiert, nachdem sie an heftigem Erbrechen gelitten hatte. Am 23. September 1885 blieb die Regel wieder aus und Anfang November trat heftiges Erbrechen auf, das sich innerhalb zweier Wochen so steigerte, dass weder feste noch flüssige Kost behalten wurde. Gleichzeitig bestand Speichelfluss und Obstipation. 
Bei der Aufnahme am 27. November erhebliche Abmagerung, SchwächegefühI und starker Foetor ex ore. Zunge hochrot, Lippen mit borkigem Belag bedeckt. Magengegend stark druckempfindlich, Temperatur normal, Puls 76. Bei der inneren Untersuchung ist der Uterus mannskopfgross, anteflektiert, weich, grosse Erosion an der vorderen Muttermundslippe, starker Cervikalkatarrh.

Trotz Regelung der Diät, Bettruhe und Aetzung der Erosion keine Besserung. Erst nach Verordnung von Cer. oxal. und Verdunkelung des Krankenzimmers trat ein Umschwung ein, indem 8 Tage hindurch grosse Quantitäten flüssiger Nahrung zurückbehalten wurden, und sich das Allgemeinbefinden deutlich hob. Dann setzte aber das Erbrechen mit grosser Heftigkeit von neuem ein, und man musste nun zur Dilatation des Muttermundes (nach Copemann) schreiten. Diese wird mit einem Dilatatorium vorgenommen, und nach mehrfacher Wiederholung sistiert das Erbrechen 8 Tage lang völlig, so dass die Patientin soweit gekräftigt ist, dass sie das Bett verlassen kann, Temperatur war so lange niemals über 37,6 gewesen, Puls nie über 96. Urin, obwohl an Menge vermindert, zeigt kein Eiweiss.

Da tritt am 18. Dezember das Erbrechen von neuem auf und nimmt einen durchaus perniziösen Charakter an. Es wiederholt sich innerhalb von 12 Stunden ca. 30 mal und erfolgt auch ohne Nahrungsaufnahme. Es schliessen sich Ohnmachtsanwandlungen und Nasenblutungen an, wiederum starker Foetor ex ore, rapider Kräfteverfall. Dilatation des Muttermundes ohne Erfolg. Temperatur steigt auf 38,3, Puls 112, kein Eiweiss im Urin. 21. Dezember Erbrechen bluthaltiger Massen. 22. Dezember Einleitung des künstlichen Aborts mittels Eistichs. Geburt eines 4monatigen Fötus, Aufhören des Erbrechens. 23. Dezember. Ikterus, der sich im Laufe des Tages deutlich verstärkt, Leberdämpiung zeigt keine Abnahme, Extremitäten kiühl, Radialpuls sehr klein, 120, Temperatur 36,5, Bewusstsein frei. Abends wird noch ein zweiter Fötus ausgetrieben, mehrfache Blutung aus der Nase und dem Zahnfleisch; der katheterisierte Urin ist auch bluthaltig. 24. Dezember Sopor, Tod 6 Uhr früh.

Sektionsbefund: Allgemeiner Ikterus, Unterhautfett wenig reichlich, Muskulatur trübe. In der Bauchhöhle $50 \mathrm{ccm}$ stark hämorrhagisch gefärbter Flüssigkeit, Peritoneum von kleinen Blutungen durchsetzt.

Milz vergrössert, Pulpa graurot, weich, fast zerfliesslich.

Im Magen: Mässige Mengen kaffeebraunen Inhalts, Schleimhant. intensiv gelb, zeigt zahlreiche punktförmige Hämorrhagien und einzelne Erosionen.

Leber sehr klein, Frontaldurchmesser $25 \mathrm{~cm}$, Sagittaldurchmesser $15^{1 / 2} \mathrm{~cm}$, Dickendurchmesser $5 \mathrm{~cm}$, Gewicht $748 \mathrm{~g}$. Peritonealüberzug klar und durchscheinend. Lebergewebe von Fäulnisgasen durchsetzt, auffallend gelb und trübe, azinöser Bau eben wahrnehmbar, dadurch, dass die Zentren der Läppchen etwas dunkler und schwach rötlich gefärbt erscheinen. In den Gallenwegen dünnschleimige, olivenfarbige Galle, das Lumen der Gallenwege überall frei.

Nieren von normaler Grösse, Kapsel adhärent, nur mit Substanzverlusten trennbar, Oberfläche schwach granuliert, von bräunlichgelber Farbe, auf dem Durchschnitt Rinde getrübt, braungelb, Mark blutreich.

Uterus faustgross, enthält spärlich Eihautreste und frische Blutgerinnsel.

Anatomische Diagnose: Status puerperalis recens, Ikterus, akute 
gelbe Leberatrophie, frischer Milztumor. Multiple Ekchymosen und Hämorrhagien. Chronische interstitielle und akute parenchymatöse Nephritis.

Bei der mikroskopischen Untersuchung der Leber fand sich eine erhebliche Verkleinerung der Acini, ebenso sind die meisten Zellen stark atrophisch, ihre Anordnung zu Balken ist beinahe an allen Orten aufgehoben, sie liegen einzeln oder in kleinen Gruppen regellos nebeneinander. Die Kerne färben sich nur schwach und sind schwer za erkennen. Protoplasma ist stark körnig getrübt und weist zahlreiche Fetttröpfechen auf. In den zentralen Teilen der Acini finden sich viele Gallenfarbstoffablagerungen. Die Gerüstsubstanz ist nicht auffällig. verändert, erscheint nur leicht gequollen. Die interlobulären Bindegewebszüge sind in geringem Grade verbreitert, entsprechend der Verkleinerung der Acini, die Spindelzellen sind gleichfalls körnig getrübt, daneben finden sich lymphoide Elemente und brane aus Gallenfarbstoff bestehende Schollen; die epithelhaltigen Gallenkanäle liegen entsprechend der Verkleinerung der Acini etwas dichter als normal.

Fassen wir die Eigentümlichkeiten dieses Falles zusammen, so sehen wir, dass die Kranke 4 bis 6 Wochen hindurch die Erscheinungen des unstillbaren Erbrechens dargeboten hat, und dass auch vorübergehend auf die bei dieser Erkrankung üblichen therapeutischen Massnahmen eine Besserung ihres Zustandes eingetreten ist. Da stellten sich in akuter Weise die Zeichen einer schweren Intoxikation ein, die schon klinisch die Diagnose einer akuten gelben Leberatrophie wahrscheinlich machten und innerhalb 8 Tagen zum Tode führten. Sektion und mikroskopische Untersuchung der Leber bestätigten die klinische Diagnose.

Der Autor vertritt auf Grund der Krankengeschichte und des anatomischen Befundes die Ansicht, dass sich hier an eine Hyperemesis gravidarum eine akute gelbe Leberatrophie angeschlossen habe, und ich muss dieser Auffassung durchaus beipflichten. Denn das unstillbare Erbrechen etwa als ein der Leberatrophie zugehöriges Symptom betrachten zu wollen, verbietet sich aus zwei Gründen. Erstens aus klinischen: Dauerndes unstillbares Erbrechen, das sich über Wochen hinaus hinzieht, ohne dass sich irgendwelche anderen Zeichen der akuten gelben Leberatrophie darbieten, ist innerhalb der gut bekannten und typischen Entwicklung dieses krankhaften Zustandes nicht beobachtet. Und auch der Hinweis darauf, dass möglicherweise durch die Gravidität, die ja zu bäufigem Erbrechen prädestiniere, die Initialsymptome dieser Krankheit modifiziert sein könnten, hat kein Gewicht, da ja bekanntlich Schwangere das grösste Kontingent zu dieser Affektion stellen, und die Schilderung des typischen Krankheitsbildes sich gerade auf sie bezieht ${ }^{1}$ ). Aber

1) Frerichs Klinik der Leberkrankheiten. 
auch aus anatomischen Gründen muss man die Annahme, dass die akute gelbe Leberatrophie bereits 6-7 Wochen alt sein könne, zurückweisen. Die Veränderungen der Leber sind ganz frischen Datums. Rote (atrophische) Herde, die sich sonst schon nach 2 Wochen finden, werden gänzlich vermisst. Regenerationserscheinungen, wie sie bei so langer Dauer nicht hätten ausbleiben können, sind nirgends erwähnt, obwohl sie dem Verfasser wohl bekannt sind. Vielmehr stimmt das anatomisch histologische Verhalten auffällig gut zeitlich überein mit dem während der letzten acht Tage" beobachteten Krankheitsbilde.

Als weiteren Fall führt Williams eine Beobachtung Lang's an: „Sur un cas de vomissements incoercibles à IV. mois de la grossesse. Mort de la parturiente." Arch. de tocol. et gynécol. 1893. XX. $620 / 28$.

35 jährige Frau, die noch nicht geboren, wird am 5. März in die Klinik des Professors B. aufgenommen mit der Klage, dass sie seit zwei Monaten alle genossenen Speisen mit Galle gemischt erbreche und dabei lebhafte Schmerzen in der Herzgrube habe. Seit dem 6. Dezember war die bis dahin normale Periode ausgeblieben, ron einer etwaigen Schwangerschaft wusste sie nichts. Die Fran war bereits ziemlich stark abgemagert, fühlte sich sehr schwach und hatte einen leichten Ikterus. Sie war etwa einen Monat in der Behandlung des Professors B. und wurde, da sich der Zustand kaum besserte und eine Schwangerschaft vermutet wurde, am 1. April auf die geburtshilfliche Klinik verlegt.

Hier stellt man fest: Starke Abmagerung, schlechten Allgemeinzustand, subikterische Färbung der allgemeinen Decke, Ungleichheit der Pupillen, trockene und rissige Zunge, fötiden Geruch aus dem Munde, Gingivitis. Leber nicht hypertrophisch; keine besonderen Zeichen von seiten des Herzens und der Lungen, keine Bewusstseinsstörung. Uterus reicht bis zum Nabel, kindliche Herztöne nicht wahrnehmbar. Bei der inneren Untersuchung fühlte man die völlig erhaltene, etwas aufgelockerte Cervix. Orificium externum leicht klaffend, Uterus vergrössert, fühlt sich wie ein gravider an. Puls frequent, 120; Temperatur 37. Dies Missverhältnis zwischen Pulszahl und Temperaturhöhe dauert bereits seit ihrer Aufnahme in die innere Klinik an. 2. April: Behandlung mit Sauerstoffinhalation, Puls 124, Temperatur 38, Urin: dunkel, mahagonifarben. 3. April: Einmal Erbrechen. Urinbefund: Spezifisches Gewicht 1019, Reaktion sauer, reichliches Sediment, enthält zahlreiche braune Pigmentkörnchen, Harnstoffmenge herabgesetzt, beträgt innerbalb 24 Stunden $16 \mathrm{~g}$, Harnsäuremenge nur $0,24 \mathrm{~g}$, merkliche Mengen von Albumen. Wegen des braunschwarzen Pigments nimmt man einen melanotischen Tumor als Krankheitsursache an. Bis zum 5. April keine Aenderung des Befindens, an diesem Tage verfiel die Patientin in Koma, klagte laut, zeigte Strabismus, ungleiche $\mathrm{Pu}$ pillen, Kontraktur des rechten Sternokleido, Konvulsionen und Trismus. Am 6. April ist der Zustand der gleiche, Temperatur 41,2, Puls unzählbar, etwa 200, unfreiwilliger Kot und Urinabgang. Uteruskontraktionen, bei jeder Wehe stöhnt die Fran, Die gespannte Blase wird zer- 
rissen, darauf folgt die Geburt eines $8 \mathrm{~cm}$ langen Fötus, und nach einer halben Stunde die Plazenta auf Druck; Gebärmutter kontrahiert sich gut, Puls wird immer schlechter und fadenförmig, Patientin kollabierte und stirbt in der Nacht.

Sektionsbefund: Alle Gewebe mit gelbem Farbstoff imprägniert, Verklebungen der Pleurablätter, ein einziger verkreideter Tuberkel in der rechten Lungenspitze, Hypostase beider Lungen, sehr starke Fettauflagerungen auf dem Myokard, Herz schlaff, Klappen zart, Ventrikelwand degeneriert, arteriosklerotische Plaques am Abgang der Koronararterien.

Leber: Konsistenz weich, Gewicht $1200 \mathrm{~g}$.

Nieren: Normales Aussehen, lassen sich leicht entkapseln.

Milz normal. Magen klein. Gehirn und Meningen absolut normal.

Uterus zeigt links von der Portio eine Ulzeration.

Die histologische Untersuchung von Magen und Leber ergibt folgendes: Die Pepsindrüsen zeigen eine bemerkenswerte Atrophie. Thre Zellen sind insgesamt körnig getrübt und zum grossen Teil zugrunde gegangen. Die Leberzellen zeigen alle eine ausgesprochene fettige Degeneration, man findet meist am Rande der Zellen viele Fettröpfchen, die oft zu grösseren zusammenfliessen, einzelne von ihnen weisen noch einen schwach färbbaren Kern auf; in diesen noch erhaltenen Elementen sowie in dem fettigen Detritus reichlicher Gallenfarbstoff. Im ganzen besteht eine wahre Auflösung der Leberepithelien, wie sie charakteristisch ist für die akute gelbe Leberatrophie.

Der Autor ist weit davon entfernt die Hyperemesis auf Rechnung der Leberaffektion zu setzen, vielmebr glaubt er die Portioerosion als Ursache anschuldigen zu müssen. Die Lebererkrankung ist nach ihm nur akzidenteller Natur und lediglich eine Steigerung der nach seiner Ansicht auch bei physiologischer Gravidität beobachteten Leberdegeneration. Hierzu ist Folgendes zu sagen: Die schwere Leberveränderung ist sicherlich das anatomische Aequivalent der während der letzten Tage aufgetretenen klinischen Erscheinungen, sie ist auch nicht etwas Nebensächliches sondern etwas höchst Merkwürdiges, nicht zu erklären durch Steigerung „physiologischer" Zustände, sondern ist etwas der normalen Gravidität gänzlich Fremdes. Andererseits aber geht es auch meines Erachtens nicht an die Hyperemesis als Ausdruck der akuten Atrophie aufzufassen. Denn darnach hätte diese nicht weniger als drei Monate gedauert haben müssen; das ist aber nach dem histologischen Bilde, welches alle Regenerationserscheinungen vermissen liess, unmöglich. Der akute Zerfall der Leberzellen und die nur geringfügige Gewichtsabnahme des Organs weisen darauf hin, dass die vorliegende akute gelbe Leberatrophie sich erst in ihrem Anfangsstadium befunden habe.

Ein. weiterer Fall stammt von Beatty: A case of acute 
atrophy of the liver. New York medical Record. 1895. Vol. 48. p. $274 / 75$.

Diese Beobachtung kann weder als Beleg für eine toxische Form der Hyperemesis, wie Williams meint, gelten, noch für die uns hier interessierende Frage der Beziehungen der Hyperemesis zur akuten Atrophie in Betracht kommen, da eine Hyperemesis überhaupt nicht vorgelegen hat.

Des weiteren notiert Williams einen Fall von Stone: Toxaemia of pregnancy. Amer. gynecol. 1903. IlI. p. 518-550.

28jährige Frau, seit 3 Jahren verheiratet, Menstruation immer normal, aber so schmerzhaft, dass sie häufig zu deren Linderung Medikamente gebrauchen musste. Vor zwei Jahren normale Geburt, wenige Monate später litt sie an Schmerzen im Rücken, Leibe und Neuralgien im rechten Bein, entsprechend dem Verlauf des Nervus ischiadicus. Nach Reposition des retrovertierten Uterus hörtèn die Rücken- und Leibschmerzen auf, die Neuralgien im Bein aber bestanden fort bis zu ihrer jetzigen Krankheit.

Ungefähr in der 5. Woche ihrer zweiten Schwangerschaft begannen Uebelkeit und Erbrechen, wurden aber nicht weiter beachtet bis zum Ende der 7. Woche. Zu dieser Zeit wurde der grösste Teil der Speisen und Getränke erbrochen, Puls und Temp. normal. Obwohl nichts per os gereicht wurde, blieb das Erbrechen bestehen. Der retrovertierte Uterus wurde reponiert, trotzdem bestand das Erbrechen weiter; die Beschaffenheit des Erbrochenen wechselte von einer farblosen zähen Salivation bis zu einer schwarzen, dünnen, wässerigen Flüssigkeit, die in sehr grossen Mengen ausgeworfen wurde. Puls 88. Deutlicher Schwächezustand. Der Uterus wurde dann in Chloroformnarkose entleert, innerhalb weniger Stunden wurde jedoch der Zustand der Patientin entschieden schlechter, Puls sehr schnell und klein, die allgemeine Schwäche trat noch mehr hervor. Obwohl das Erbrechen am Tage: nach der Operation mehrere Stunden lang aufhörte, begann Pat. am darauffolgenden Tage zu delirieren, wurde komatös und starb. Gelbsucht bestand nie, der Urin zeigte grosse Mengen von Eiweiss, Leuzin und Tyrosin.

Sektionsbefund: (nur die Bauchhöhle wird eröffnet.) Leber: hat sich von der Bauchwand entfernt und erreicht nicht den freien Rippenrand, ist viel kleiner als normal. Gewicht 1000 g. Oberfläche runzelig, von gelblicher Farbe, gibt dem Fingerdruck leicht nach, Schnittfäche ist glatt und ron fettigem Aussehen, Läppchen erkennbar, keine Stauung, Gefässe leer. Gallenblase enthält Galle, Gallenwege sind durchgängig.

Mikroskopisch zeigt sich, dass fast der grösste Teil der Zellen eines jeden Lobulus infolge von fettiger Degeneration zu Grunde gegangen ist. An der Grenze der Leberläppchen ist ein Wall von Zellen, die in Koagulationsnekrose begriffen sind. Die Peripherie der Läppchen ist ferner charakterisiert durch eine deutliche Hyperämie der von den Pfortaderästen stammenden Kapillaren. Die Injektion kann am gefärbten Präparate mit blossem Auge gesehen werden. Im interlobulären Binde- 
gewebe begegnet man Leukozytenansammlungen um die Gefässe herum. Die sublobularen Venen sind frei.

Nieren: von normaler Grösse und fester Konsistenz, Farbe leicht gelb, Kapsel glatt, Oberfläche der Nieren auch glatt, Rinde etwas verdickt, von gelber Farbe.

Mikroskopisch findet sich starke fettige Degeneration des Parenchyms besonders der Zellen der Tubuli contorti, keine Zeichen von chronischer Nephritis.

Dieser Fall nimmt seinem klinischen. Verlaufe nach eine Sonderstellung ein. Er verlief innerhalb von 2 Wochen tödlich. Das Erbrechen wurde zudem erst gegen das Ende dieser Frist wirklich heftig, bis dahin war es unerheblich. Aus der der Abhandlung beigegebenen Mikrophotographie kann man ersehen, dass nur die Zellen der Peripherie durch fettige Degeneration zu Grunde gegangen sind, während die der inneren zwei Drittel des Läppchens noch balkenförmige Anordnung und gute Tinktion mit Hämatoxylin aufweisen. Die Degeneration ist also noch nicht weit vorgeschritten and das entspricht völlig dem perakuten Verlauf der Krankheit. Wie hat man nun diese Fälle aufzufassen? Eine Hyperemesis gravidarum in dem Sinne, wie diese Affektion von allen Autoren unserer geburtshilflichen Lehrbücher und von den Klinikern aufgefasst und geschildert wird, ist es offenbar nicht. Denn bisher ist damit immer die Vorstellung einer wochen- und selbst monatelangen Erkrankung verknẗpft worden. Hätte man solche akuten Formen auch unter dem Begriff der Hyperemesis gravidarum zusammengefasst, so hätte es meines Erachte nie einen Streit darüber gegeben, ob es auch toxische Formen dieser Krankheit gäbe. Denn dass diese letzteren solehe sind, ist ja ohne weiteres ersichtlich.. In anatomischer Hinsicht kann der Fall als ein sehr frühes Stadium der akuten gelben Leberatrophie aufgefasst werden, in welchem klinisch der sonst für diese Krankheit so charakteristische Ikterus fehlen kann.

Der Fall Zaborsky's, Monatsschr. f. Geburtsh. u. Gyn. 1904. Bd. 20. S. $39 / 47$.

30 jährige Frau, Ipara im vierten Monat, aufgenommen am 20. IX.03. Patient hat vor 5 Wochen zu erbrechen angefangen, seit drei Wochen erbricht sie alle per os genommene Nahrung, täglich 8-10 mal.

Uterus anteflektiert, weich. Fundus zwischen Nabel und Symphyse. Ueber dem innern Muttermund fühlt man einen haselnussgrossen Myomknoten. Der äussere Muttermund ist für die Fingerspitze offen. Urin schwach sauer, Farbe dunkelbraungelb, kein Eiweiss oder Zucker. Die Untersuchung der Organe ergibt keine Abweichungen von der Norm. 
Therapie: Milchdiät, Salzwassereinläufe in den Darm und unter die Haut; jedoch ohne Erfolg, per os wird nichts vertragen, Puls 92-104.

Am 5. X. wird die Cervix mit Jodoformgaze tamponiert, um durch die Erweiterung entweder das Erbrechen zum Stillstand zu bringen oder den Abort einzuleiten. Das Erbrechen lässt auch zunächst nach, setzt aber am nächsten Tage mit unverminderter Heftigkeit wieder ein. Die Nacht sehr unruhig, häufig Schmerzäusserungen.

Am 7. X. Temp. 38, Puls 128. Ausgesprochener Ikterus, der heute zum ersten Male bemerkt wird. Abort wird nunmehr künstlich beendet; jedoch keine Besserung, sehr häufiges Erbrechen, Puls 136.

Am 9 X. Exitus letalis.

Sektionsbefund1): Diagnose: Atrophia hepatis flava. Degeneratio adiposa renum, parenchymatosa myocardii. Enteritis partis infimae ilei, partim diphtheritica. Status uteri post abortum. Corpus luteum verum ovarii dextri. Erosiones tunicae mucosae ventriculi permultae. Myoma uteri subserosum.

Der Magen enthält etwa $100 \mathrm{ccm}$ graubraune trübe Flüssigkeit. Die Schleimhaut ist von mittlerer Dicke, blass. An der kleinen Kurvatur entlang finden sich in einem etwa handtellergrossen Bereiche der Schleimhaut dicht nebeneinander mohn- bis hirsekorngrosse Erosionen mit blassem Grunde.

Die Leber ist auffallend klein, Gewicht $1100 \mathrm{~g}$, Ränder verdünnt, Oberfläche fein gerunzelt. Lebersubstanz schlaff, bröcklig, von mässigem Blutgehalt, von teigiger Konsistenz. Dellen vom Fingerdruck bleiben bestehen. Die Schnittfläche der Leber ist gallig verfärbt, gelb mit einem Stich ins Grünliche, die Leberläppchen sind klein, die Zeichnung der Leber verschwommen. In der Mitte der Läppchen erkennt man eine kleine bräunliche Vertiefung.

Die mikroskopische Untersuchung der Leber und Nieren: Die Leber zeigt abwechselnd hellere und dunklere Partien (van GiesonPräparat). Innerhalb der dunkler gefärbten ist die Anordnung der Leberzellen im grossen und ganzen gut erhalten. Diese Partien lehnen sich an die mit spärlichen Rundzellen infiltrierten periportalen Bindegewebszüge an. Die heller gefärbten lassen nur eine undeutliche Struktur des Lebergewebes erkennen, insofern hier die einzelnen Zellen nicht mehr zu Reihen angeordnet sind, sondern regellos nebeneinander liegen. Die hellere Färbung wird dadurch bedingt, dass die Kerne fast gar keinen Farbstoff angenommen haben. Die Form dieser Zellen ist eine ganz unregelmässige, es sind zum grössten Teile nur noch kernlose sehr atrophische Elemente, die, wie das Sudanpräparat zeigt, stark mit Fetttröpfchen infiltriert sind. Die Gallenkapillaren sind vielfach mit galligen Massen ausgefüllt. Diese zuletzt beschriebenen Zonen begleiten in mehr oder minder breiter Ausdehnung die zentralen und sublobularen Venen, deren bindegewebige Wand verdickt ist.

Wir sehen also einen degenerativen Leberprozess vor uns, der sich in den Zentren der Leberläppchen abspielt, während die peripheren Teile derselben noch gut erhalten sind.

1) Herrn Privatdozent Dr. Entz danke ich auch an dieser Stelle für die Ueberlassung des Sektionsprotokolles, sowie der ganzen Leber zur Entnahme von Stücken zwecks mikroskopischer Untersuchung. 
Die mikroskopische Untersuchung der Nieren zeigt gut erhaltene Glomeruli, dagegen ist der weitaus grösste Teil der gewundenen Harnkanälchen nekrotisch geworden und von scholligen, abgestossenen und zu Grunde gegangenen Zellresten ausgefüllt. Der dünne Schenkel der Henleschen Schleife ist stark verfettet. In einzelnen geraden Harnkanälchen finden sich hyaline Zylinder.

Auf Grund dieser Befunde gelangen wir zu der Einsicht, dass zweifellos toxische Einflüsse auf diese Organe eingewirkt haben, durch welche an der Leber eine Veränderung nach Art der akuten gelben Atrophie hervorgerufen wurde. Dieser Prozess ist aber zu frisch und zu wenig vorgeschritten, als dass er etwa als anatomische Grundlage des seit zwei Monaten bestehenden Krankheitsbildes der Hyperemesis grav. aufgefasst werden könnte.

Weiterhin hat Ewing Beiträge zu der vorliegenden Frage gelietert, und zwar sind es vier Fälle von akuter gelber Leberatrophie, die ich einer mir freundlichst von Prof. Williams in Baltimore zur Verfügung gestellten Arbeit von. Ewing and Wolf: The clinical significance of the urinary nitrogen. The metabolisme in the toxemia of pregnancy. Amer. journ. of obstetr. Vol. LV. No. 3 entnehme.

I. 35jährige Frau, vier ausgetragene Geburten und drei FehIgeburten innerhalb von 11 Jahren. Seit dem Beginn des zweiten Monats dieser Schwangerschaft, seit dem 8. II. 1905 litt sie an beständigem Uebelsein und Erbrechen, Verminderung des Sehvermögens, Oedem der Beine, Mattigkeit. Im Juni wurde der Urin dunkel. Aufnahme am 29. VII., nachdem sie einmal Konvulsionen gehabt hatte. Etwas benommen, mässiges Erbrechen, Puls 80 von mässiger Spannung. Retinitis albuminuriea. Während die künstliche Frühgeburt eingeleitet wird, wird die Patientin komatös. Der Puls liess nach, erholte sich aber nach einer Infusion wieder. 30. VII. wurde sie gelb. 2. VIII. wieder Koma, das bis zu dem am 9. Tage erfolgenden Tode anhielt.

Die Sektion ergab ein sehr merkwürdiges Aussehen der Leber; etwa die Hälfte des Organs war von zahlreichen anämischen Infarkten, die einen Durchmesser von $1 / 8$ bis 1 Zoll hatten, durchsetzt. Einzelne davon waren frisch, andere älteren Datums und von jungem Bindegewebe umgeberr. Einige von diesen zeigten Verkalkung ${ }^{-1}$ ) der nekrotischen Leberzellen. Das übrige Parenchym wies nur mässige körnige Degeneration auf. In der Niere fand sich eine schwere akute diffuse neben einer produktiven Entzündung.

Diese Beobachtung gehört überhaupt nicht zu den hier abzuhandelnden Fällen, da eine der akuten gelben Leberatrophie ähnliche Affektion gar nicht vorgelegen hat, vielmehr jene Veränderung, wie wir sie von der Eklampsie her kennen. Als eine

1) Diese Verkalkung der Leberzellnekrosen ist ein überaus seltener Bỏfund. Ceelen hat einen ähnlichen Fall beobachtet (Virchow's Arch. Bd. 201). 
Hyperemesis können wir den Fall auç darum nicht ansprechen, da wir bei letzterer Oedeme und Abnahme der Sehkraft, also deutliche Zeichen einer schweren Nephritis vermissen.

II. 30jührige Frau, gut genährt, hatte $3 \mathrm{mal}$ geboren, keine Aborte, und ist jetzt im 7. Monat der Schwangerschaft; vor 4 Tagen fiel sie eine Treppe hinunter, und drei Stunden später begann sie zu kreissen. Von Uebelkeiten und Erbrechen ist nichts bekannt. Bei ihrer Einlieferung am 14. IV. war die Patientin etwas benommen. Puls 100, klein und weich, leichte Zyanose, keine Gelbsucht. Erbrechen dunkelbrauner Massen, wird noch an demselben Tage komatös und stirbt abends.

Die Leber wog 4 Pfund, Parenchym gelb und mürbe. Mikroskopisch waren die Zellen stark verfettet und überall zerfallen, jedoch nicht nekrotisch. Starke Blutfïlle des Organes. Nieren ebenfalls sehr verfettet.

Auch dies ist kein Fall von Hyperemesis. Anatomisch kann man auch nicht von Atrophie, sondern nur von akuter Fettdegeneration sprechen.

III. Frau, die die klinischen Erscheinungen der gelben Leberatrophie darbot, auch Schwund der Leberdämpfung und nach 20 tägiger Krankheit starb. Sektion fand nicht statt.

IV. 23jährige Ipara, gut genährt, Säuferin, anämisch, klagt zum ersten Mal am 3. V. über Schmerzen in Leib und Rücken und über anhaltendes Erbrechen nach den Mahlzeiten. Am 9. V. wird ein leichter Ikterus bemerkt. Darauf wurde die künstliche Frühgeburt eingeleitet, und um $11 \mathrm{Uhr}$ abends ein lebendes 7-Monatskind geboren. Patientin fühlte sich aber nicht wohl, brach häufig gallig gefärbte Flüssigkeit, wurde immer stärker gelb, und der Puls sehr frequent und klein. Nach einer am 11. d. M. vorgenommenen intravenösen Kochsalzinfusion besserte sich der Puls vorübergehend, sie kollabierte bald wieder. Das Erbrechen liess allerdings nach, aber die Gelbsucht nahm zu, ebenso traten Delirien, Koma, Stupor und Konvulsionen in den Armen ein bis die Patientin am 13. starb.

Die Leber wog 3 Pfund, war dunkel, weich und knisterte im linken Lappen Im mikroskopischen Präparat zeigte sich zumeist völlige Vernichtung des Parenchyms, nur wenige Leberzellen waren übrig geblieben. Die Nieren zeigten nur einen mässigen Grad von körniger Degeneration.

Auch hier handelt es sich ähnlich wie in dem Falle Stone's um einen akuten innerhalb von 10 Tage zu Tode führenden Prozess, der auch in das Gebiet der akuten gelben Leberatrophie hineingehört, obwohl die Atrophie keinen nennenswerten Grad erreicht hat.

Streng genommen bot also von den 4 Fällen Ewing's nur einer das Bild der akuten gelben Leberatrophie, aber ohne Hyperemesis (Fall III). Die übrigen können gleichfalls nicht als wahre Hyperemesisfälle angesehen werden. Für die Frage der Beziehung 
dieser Erkrankung zur akuten gelben Leberatrophie kommen sie daher alle nicht in Betracht.

Der Fall von Williams; The John Hopkins Hosp. balletin. Vol. XVII. p. $71-92$.

Erste Vorstellung am 22. IV. 1903. 28jährige Frau, gross, von zartem Aussehen, ist seit 2 Jahren verheiratet und noch nicht schwanger gewesen; letzte Periode am 10. II., s Tage danernd. Im März und April waren die Menses nur angedeutet; sie hat schon viel an Uebelkeit gelitten. Bei der Untersuchung war der Uterus von der Grösse wie sie dem zweiten Schwangerschaftsmonat entspricht und aufgelockert, so dass über die Gravidität kein Zweifel sein konnte.

Wenige Tage später kam die Patientin wieder und klagte sehr iiber Uebelkeit und Erbrechen, der Stuhlgang wurde geregelt, ferner Pepsin und Argentum nitricum verordnet. Als dies vergebens war, wurden noch mehrere andere Medikamente gleichfalls ohne Erfolg angewendet; allmählich wurde aber das Erbrechen so heftig, dass die Patientin unfähig war überhaupt irgend etwas bei sich zu behalten, so dass sie nur per rectum ernährt wurde. Sie erhielt täglich 2 Nährklistiere und einen Salzwassereinlauf. Nichtsdestoweniger wurde die Frau immer schwächer und magerer und litt schwer unter dem Erbrechen. Der Puls war allmählich von 70 auf 92 in der Minute gestiegen.

15. V. Profuser Speichelfiuss und dauerndes Erbrechen kleiner Mengen einer dunkelbraun aussehenden Flüssigkeit, klagte über starke Schmerzen in der Magengegend. Ungeachtet ihres verhältnissmässig langsamen Pulses erschien der Abort angezeigt, der am folgenden Tage zur Ausführung gelangte.

Patientin vertrug die Operation zunächst gut und war die folgenden 18 Stunden frei von Uebelkeit und Erbrechen, darauf aber setzten sie wieder ein und Patientin erbrach kleine Mengen kaffeegrundähnlicher Massen fast ohne Anstrengung, allmählich wurde der Puls schneller und trotz Nährklistier, subkutanen Kochsalzinfusionen, Digitalis und Strychnin immer frequenter.

19. V. Puls 119. Noch weitere Steigerung der Pulsfrequenz bis zu dem abends erfolgenden Exitus. Während der Ietzten 12 Stunden war sie völlig bewusstlos. Der Urin war vor der Einleitung des Aborts mehrere Male untersucht worden, enthielt weder Eiweiss noch Zylinder. Nach der Operation hatte eine Untersuchung nicht mehr stattgefunden.

Sektionsprotokoll (Dr. Marshall). Diagnose: Frischer Scheiden- und Cervixriss. Ein Teil der Plazenta ist fest mit der Uteruswand verwachsen. Fettige Degeneration, zirkumskripte Nekrosen und Ikterus der Leber, fettige Degeneration und Ikterus der Nieren. gleich.

Keine Oedeme, keine Gelbsucht, geringes Fettpolster, Pupillen

Herz: Klappen zart, Muskulatur schlaff, opak, gelblich offenbar durch Gallenfarbstoff.

Magen enthält etwa 1/2 Liter dunkler Flüssigkeit, in der sich Blutkörperchen und Galle befinden, Mukosa normal.

Leber: Gewicht $1000 \mathrm{~g}$, klein, von deutlich gelber Farbe, von glatter Oberfläche und weicher Konsistenz. Beim Aufschneiden zeigte 
sie sich sehr fettreich und von galliger Färbung. Schon mit blossem Auge sind degenerierte und nekrotische Flecken sichtbar. Die Kapillaren treten zwischen den gelblich gefärbten Leberbalken deutlich hervor. Abgesehen davon, dass die Degeneration nicht so stark ist, erinnert das Aussehen sehr an das der akuten gelben Leberatrophie. Gallenblase und Gallenwege normal.

Nieren: Beide Nieren sehen gleich aus und sind beträchtlich vergrössert, die Kapsel lässt sich leicht abziehen, Oberfläche gallig gefärbt, opak, zeigt keine Gefässe. Die Rinde ist $7-8 \mathrm{~mm}$ breit, sehr gelb, trïbe granuliert und leicht erhaben über die Oberfläche der Pylamiden. Zeichnung verwischt, weder Gefässe noch Glomeruli kömen erkannt werden. Die Pyramiden sind blass und ihre Peripherie zeigt. Linien und Flecken von fettigem Aussehen. Nierenbecken normal.

Mikroskop ische Untersuchung. Leber: Bei schwacher Vergrösserung haben die mit Hämatoxylin und Eosin gefärbten Schnitte ein merkwürdig gesprenkeltes Aussehen. Ungefähr die Hälfte des Gesichtfeldes wird eingenommen von runden oder unregelmässig begrenzten Gebieten, die schön rot durch Eosin gefärbt sind und von einander durch weniger leuchtend tingiertes Gewebe getrennt werden. Bei genauer Prüfung sieht man, dass diese Partien den Zentralteilen der Leberläppchen entsprechen, die sämtlich in den Prozess einbegriffen. sind. Die einzelnen Läppchen sind gut von einander abgegrenzt, und die interlobulären Strecken bieten ein normales Aussehen dar, sowohl bezüglich des Bindegewebes wie der Blutgefässe und der Gallengänge. Nirgends Hämorrhagien oder Gefässthrombosen. In jedem Läppchen kann man 3 Zonen unterscheiden: periphere, intermediäre und zentrale. Die peripheren bestehen aus einer oder zwei Reihen wirklich normaler Leberzellen mit deutlich gefärbten Kernen und schwach granuliertem Protoplasma. An manchen Stellen ist diese schmale Zone normaler Zellen unvollständig, so dass die Zellen der intermediären Zonen benachbarter Läppchen direkt aneinander grenzen. Die intermediären Zonen sind verschieden breit; im allgemeinen nehmen sie die äussere Hälfte des Abstandes zwischen Zentralvene und Peripherie ein. Sie werden gebildet aus grossen unregelmässig begrenzten Zellen, deren Kerne schwach gefärbt sind und deren Protoplasma zumeist ganz eingenommen wird von zahlreichen Vakuolen, die knapp so gross sind als wie die Kerme. Diese waren anscheinend ursprünglich mit Fetttröpfchen ausgefüllt, die aber durch Härtungsmittel ausgezogen worden sind. In dieser Zone ist die starke Füllung der intralobulären Kapillaren bemerkenswert. Die Bindegewebselemente sind wohl erhalten und scheinbar stellenweise vermehrt. Leukozyten finden sich nicht. Die zentralen Partien der Läppchen, welche die andere Hälfte des Parenchyms eines jeden Lobulus umfassen, werden von den mittleren Zonen abgegrenzt durch eine unregelmässige, wellige Linie, aber stellenweise sieht man deutlich beide Zonen in einander itbergehen. Diese zentralen Partien färben sich leuchtend rot mit Eosin; in vielen Läppchen bestehen sie nur aus nekrotischen Zellen mit grob gekörnter Struktur ohne jede Spur von Kernen. In anderen kann gelegentlich ein Bindegewebskern unterschieden werden, während in seltneren Fällen degenerierte Kerne einzelner Leberzellen mit Hämatoxylin eine schwache Färbung annehmen. In mehreren Läppchen ist die Zentralvene wohl erhalten, in anderen liegt an ihrer Stelle ein Haufen von Kernen, in noch anderen ist jede Spur von ihr verschwunden. 
Nieren; Die Schnitte zeigen, dass die Glomeruli völlig normal sind. Dagegen ist der sekretorische Teil der Nierenkanälchen meist ganz nekrotisch und die Zellen der Tubuli contorti in unregelmässige, grob gekörnte und vakuolisierte Massen, die nur noch gelegentlich einen schwach gefärbten Kern zeigen, umgewandelt. An vielen Stellen sind die Lumina der Harnkanälchen verlegt, während sie in anderen mehr oder weniger mit körnigem, auch rote Blutkörperchen enthaltendem Material ausgefüllt sind. Die Sammelröhren dagegen scheinen völlig normal, ebenso der bindegewebige Anteil der Nieren.

Auch in dieser Beobachtung ist ein mehrwöchiges, der gewöhnlichen Form der Hyperemesis durchaus ähnliches Krankheitsstadium in die Erscheinung getreten. Daran schloss sich - nach einer anf die künstliche Entbindung folgenden vorübergehenden Besserung - eine Verschlimmerung der bis dahin beobachteten Krankheitserscheinungen an und innerhalb 3 Tagen trat in tiefem Koma der Exitus letalis ein. Bemerkenswert ist hier die relativ kurze Dauer des hyperemetischen Stadiums, und ebenso die kurze Frist, die für die terminalen Symptome bemessen war. Das vollentwickelte Bild der akuten gelben Leberatrophie kam hier nicht zustande, selbst der Ikterus fehlt. Nach dem anatomischen Bilde kann aber kein Zweifel sein, dass die in Rede stehende Leberaffektion wirklich bestanden hat, jedoch hebt auch der Obduzent hervor, dass die Degeneration des Organs nicht den für diese Erkrankung üblichen Grad erreicht habe. Das müsste den, der die Lebererkrankung schon von Beginn der Hyperemesis ab datieren wollte, befremden, da innerhalb von nahezu 4 Wochen - solange hatte das ganze Leiden gewährt - sich sonst das typische anatomische Bild der akuten gelben Leberatrophie voll zu entwickeln pflegt. Darum möchte ich auch hier glauben, dass sich die Leberaffektion erst später entwickelt habe, so spät, dass sie auch im klinischen Bilde einen adäquaten Ausdruck noch nicht gefunden hat.

Diesen von anderer Seite mitgeteilten Fällen vermag ich nun einen neuen Fall eigener Beobachtung hinzuzufügen.

\section{Krankheitsgeschichte.}

A. B., 21 Jahre alt, Ipara, hat Ende Oktober zum letzten Male menstruiert und nun seit 5 Wochen Erbrechen, das früher noch stärker war wie jetzt und unabhängig vom Essen eintritt. In den letzten Tagen Kopfschmerzen.

1.3. I. 1912 Eintritt in die Klinik. Mittelgrosse, grazile Person in leidlichem Ernährungszustande. Die Untersuchung der inneren Organe ergibt keine Besonderheiten. Bei der inneren Untersuchung zeigt sich der Uterus deutlich vergrössert, anteflektiert und weich. Urin enthält Spuren von Eiweiss und Leukozyten. Patientin erbricht 2 mal. 14. I. 
Erbrechen nach Genuss kühler Milch. 16. I. Albumen in Spuren, Leukozyten im Urin. $2 \mathrm{mal}$ Erbrechen. 17. 1. $2 \mathrm{mal}$ Exbrechen. 20. I. Albumen in Spuren nachweisbar. 21. I. Erbricht nur morgens. 22. I. Erbricht wieder alles. 23. I. Gewichtsabnahmne in einer Woche 2550 g. 24. I. Erbricht dauernd alles. Im Harn Eiweiss, keine Formelemente. 26. I. Die innere Untersuchung ergibt keine Abweichung von der Norm. Zunge weisslich belegt, starker Foetor ex ore. Albumen im Urin heute nicht nachweisbar. Erbrechen. 31. I. Da das Erbrechen fortbesteht, ohne dass eine organische Ursache dafür auffindbar wäre, wird die medizinische Klinik konsultiert. Hier wurde eine subikterische Verfärbung der Skleren, Tachykardie, Subazidität und Anämie festgestellt. Im Urin wird Eiweiss und Gallenfarbstoff in Spuren gefunden. 1. II. Patientin wird per Klysma emährt und erhält Kochsalzeinläufe. Am 4. II. Urinmenge gering $250 \mathrm{ccm}$. Es findet sich darin weder Albumen noch Zylinder oder Leukozyten. Die Patientin ist sehr schwach. 8. II. Wieder Spuren von Albumen im Urin, jedoch keine Zylinder.

10. II. Seit gestern abend ist die Patientin zusehends apathischer. Das Gesicht ist eingefallen. Zunge ist trocken, fuliginöser Belag der Zähne und des Zahnfleisches. Ikterische Verfärbung der Skleren etwas stärker, weder Vergrösserung noch Verkleinerung der Leber nachweisbar. Patientin erhält 1 Liter Kochsalzlösung subkutan. Im Urin finden sich spärliche Epithelzylinder. Urobilin +, Bilirubin - .

11. II. Patientin reagiert nur auf lautes Anrufen. der Mund ist halb geöffnet. An der Stelle des Infusionsstiches zahlreiche kleine Blutaustritte, Puls 160 in der Minute.

Es wird wegen zunehmender Verschlimmerung und Somnolenz Einleitung der künstlichen Frühgeburt beschlossen. Unter Aetherrausch Dilatation der Cervix und Sprengung der Blase.

12. II. Allgemeineindruck nicht verändert. Patientin reagiert kaum auf Anruf, Puls ist sehr frequent, wenn auch voller. Patientin stöhnt von Zeit zu Zeit und schreî́ zuweilen laut auf Abdomen stark vorgewölbt, überall Darmschall. Nach Entleerung der Gase durch ein Darmrohr ist der Leib viel weicher. Ausgesprochenes Koma.

13. II. Puls 190. Ikterische Verfärbung der Skleren ist kaum bemerkbar, Abdomen wenig gespannt, überall tympanitischer Schall. Leberdämpfung nicht verändert. Bei der Eindampfung einer durch 24 Stunden gesammelten Urinmenge lässt sich sicher Leucin und Tyrosin nachweisen. Zunehmendes Koma, Dyspnoe. Tod abends um 11 Uhr.

\section{Sektionsprotokoll.}

Diagnose: Fettige Degeneration der Leber mit beginnender Atrophie und starkem lkterus. Pleura-Blutungen. Fettige Degeneration der Niere mit Ikterus. Schwangerschaft 3.-4. Monat.

Der Panniculus adiposus der Bauchhaut ist reichlich entwickelt, ebenso ist das subepikardiale Fett in hinreichender Menge vorhanden. Die Oberfläche der linken Lunge zeigt punktförmige Blutungen über dem Unterlappen. Gefässe frei. Die rechte Lunge zeigt keine Anomalien des Pleuraüberzuges. Auch hier ist das Gewebe überall lufthaltig. Herz vielleicht etwas grösser als die Faust. Am Epikard ausser mässiger Entwicklung des Fettpolsters keine Anomalien und keine Blutungen, ebensowenig wie am Endokard. Herzmuskel von normaler Konsistenz und Farbe. Normale Wanddicke, Klappen intakt. 
Milz kleiner als normal, schlaft. Pulpa dunkelblau-rot, ziemlich fest, Zeichnung deutlich.

Magen zeigt im Bereiche des Fundus zarte, kapillare Hyperämie, keine sichere Blutung. Darminhalt gallig gefärbt.

Leber dentlich verkleinert, Gewicht $1080 \mathrm{~g}$, Kapsel glatt, faltet sich nicht. Das Organ hat eine ockergelbe Farbe, besonders auf dem Durehschnitt. Konsistenz leicht vermindert, etwas muürbe. Die Zeichnung des Leberparenchyms sehr deutlich, die Zentren der Lüppchen treten gleichfalls durch ihre dunkelgrüne Färbung, welche sich von der hellen Farbe des übrigen Parenchyms abhebt, klar hervor.

Gallenblase gefiullt mit dunkelschwarzer Galle; Gallenwege durchgängig.

Nieren sind sehr schlaff, Kapsel leicht abziehbar, Zeichnung deutlich, Rinde gelb, Mark bläulich rot; Rinde hat einen ikterischen Fettglanz.

Harnblase. Inhalt trübe, stark ammoniakalisch riechender braungefärbter Urin.

Uterus von der Grösse eines Kindskopfes, fluktuiert, enthält noch die Frucht.

Mikroskopische Untersuchung. Leber: Mit Alkohol behandelte Schnitte zeigen bei schwacher Vergrösserung überall im Leberparenchym helle rundliche Lücken von meist beträchtlicher Grösse. Der protoplasmatische Zellrest ist namentlich in den innersten Zonen des Läppchens, welche der Zentralvene benachbart sind, nur noch spurenweise vorhanden, während die intermediären Teile des Läppchens und auch die peripheren, letztere allerdings weniger reichlich, gut färbbares Protoplasma enthalten. Infolgedessen tritt schon ein deutlicher Lnterschied der zentralen Partien gegenüber den peripheren zu Tage, insofern die zentralen in gefärbten Präparate viel heller erscheinen als die peripheren. Das verschiedene Verhalten dieser beiden Teile des Läppehens wird noch dentlicher dadurch, dass in den zentralen Partien eine Pigmentierung sich findet, die in den peripheren fehlt. Die trabekuläre Anordnung der Leberzellen ist, wie man sich an Gefrierschnitten überzeugen kann, gut exhalten, die Zwischenräume zwischen den Balken sehr eng, die Balken selbst in den lichten zentralen Partien schmäler als in den peripheren.

Im Sudanpräparat zeigt sich, dass die runden Lücken in den Zellen sich rot färben, also Fettröpfehen sind. Besonders dicht liegt das Fett in den zentralen Partien, spärlicher in der intermediären Zone und wieder etwas dichter in der Peripherie, aber doch nicht in dem Grade wie im Zentrum. Bei schwacher Vergrösserung hat man den Eindruck der einfachen, allerdings zentral am stärksten ausgeprägten Fettinfiltration.

Bei stärkerer Vergrösserung zeigt es sich, dass man an der Peripherie der Lobuli einzelne Zellen nicht sicher von einander abgrenzen kaun. Je näher man dem Zentrum kommt, desto mehr tritt eine durch Querspalten hervorgebrachte Segmentierung des Balkens ein, woraus grössere und kleinere Zellkomplexe resultieren. In unmittelbarer Umgebung der Zentralvenen bestehen diese nur aus wenigen Zellen. Fasst man diese letzteren näher ins Auge, so sieht man, dass der spärliche Rest von Protoplasma, der hier noch anzutreffen ist, fast völlig von einem grüngelben Pigment beladen ist. Dieses schiebt sich sternförmig zwischen die grossen Fettropfen hinein. Der Kern ist daneben oft noch wahrnehmbar, zeigt auch die Chromatinfigur der normalen Leberzellen, 
In andern Zellen dagegen ist der Kern geschrumpit, eckig, stark färbbar, pyknotisch. Ist hier aber noch die normale Konfiguration der Zelle bewahrt, so sieht man daneben alle Stadien des Zerfalls. Zunächst sind die Grenzen der Zellen nach den Blutkapillaren hin unscharf und unregelmässig, Fettropfen treten aus dem Zelleibe heraus, und schliesslich resultiert nur der ikterische Zellrest, der noch den Kern aufweisen kann und noch das Aussehen einer allerdings stark geschrumpften Leberzelle hat, oder aber der Zellcharakter wird völlig. eingebüsst, der Kern verschwindet, man sieht nur noch ikterische Schollen und Bröckel, bis auch diese verschwinden. Ansser diesen Zeichen ikterischer Pigmentierung findet man auch starke Füllung der Gallenkapillaren, ähnlich wie bei der Gallenstaung durch mechanische Momente. Jedoch tritt diese Anhäufung von Gallenfarbstoff in den präformierten Räumen an Ausdehnung zurück gegenüber der diffusen Zellpigmentierung. Es ist wohl ohne weiteres verständlich, dass durch den Untergang der centroacinösen Elemente. ohne dass auch nur der geringste Ansatz einer Neubildung von Leberzellen wahrzunehmen ist, ein nicht geringer Schwund des Organs zustande kommen muss. Etwa 1/3 des Lebergewichts ist auf diese Weise eingebüsst worden.

Niere. Beginnen wir mit der Rinde, so fällt uns zunächst die Beschaffenheit der gewundenen Harnkanälchen auf. Diese sind in ihrem Dickendurchmesser stark verbreitert und lassen zum allergrössten Teile völlig die Zellkerne vermissen; man trifft nur hin und wieder in den Zellen, welche das einstige Lumen dieses Abschnittes der Harnkanälchen bildeten, einen Kern. Die meisten Zellen, welche sich an der Auskleidung der gewundenen Harnkanälchen beteiligen, sind dagegen kernlos. Dabei fällt, wie schon angedeutet, die völlige Aufhebung des Lumens ins Auge. Die Zellen sind oft zu einer gemeinsamen nekrotischen Masse zusammengeschmolzen; viele von ihnen enthalten, der Membrana propria benachbart, gelbes, gallenfarbstoffhaltiges Pigment. In diesem Labyrinth der gewundenen Harnkanälchen fallen einzelne von solchen Harrikanälchen auf, deren Kerne wohl erhalten sind -- wenigstens zum grössten Teile - und die sich ihrem Aussehen nach als Schaltstücke ausweisen. Die in die Rinde einstrahlenden Ferrein'schen Pyramiden zeigen teils wohl erhaltene, teils gleichfalls in voller Nekrose begriffene Henle'sche Schleifen. Nach der Grenze zur Pyramide hin hört die Nekrose ganz auf, die Zellen der geraden Harnkanälchen der Pyramide sind durchaus wohl erhalten. Die durch Nekrose zugrunde gegangenen Zellen zeigen zum allergrössten Teil eine sehr starke basalständige Fettinfiltration, die an einem kleineren Teil der nekrotischen Elemente nicht so dicht ausfällt, aber fast überall deutlich nachweisbar ist. Auch die geraden Harnkanälchen der Marksubstanz enthalten ganz feintröpfiges Fett in den im übrigen wohl erhaltenen Zellen.

Das Wichtigste des anatomisch-pathologischen Befundes lässt sich dahin zusammenfassen, dass eine hochgradige Verfettung der Leber vorliegt, die sich sowohl in den Zentren als auch in der Peripherie der Läppchen lokalisiert und nur in den intermediären Partien einen geringen Grad aufweist. Die Verfettung der zentralen Acinusabschnitte weicht von der der peripheren insofern ab, als die ersteren ausserdem ikterische Pigmentierung und in einer 
schmalen Zone um die Zentralvene herum auch Zellzerfall aufweisen. Letzterer kommt wesentlich auf dem Wege der Verfettung, weniger durch Kernschwund zustande. An der Niere ist die hochgradige Verfettung, namentlich der gewundenen, zum geringeren Teil der geraden Harnkanälchen sowie die Nekrose und ikterische Pigmentierung der ersteren besonders bemerkenswert. Es fragt sich nun, wie soll man diese Befunde deuten. Eine Fettdegeneration der Leber mit beginnender Atrophie, eine Fettdegeneration der Niere in dem hier obwaltenden Umfange können nur durch infektiöse oder toxische Noxen bedingt werden. Für eine Infektion haben wir gar keinen Anhaltspunkt, und die Untersuchung der Leber auf Bakterien hatte auch ein negatives Resultat. Man kann daher die Leberveränderungen nur auf toxische Ursachen zurückführen. Auch hier handelt es sich mithin um ein länger als 2 Monate dauerndes unstillbares Erbrechen, das in den letzten 4 Tagen das Krankheitsbild der akuten gelben Leberatrophie darbot. Insofern ist die Beobachtung für die Frage der Beziehungen beider Erkrankungen zueinander ron zweifelloser Wichtigkeit. Anatomisch und besonders histologisch aber ist die Leberaffektion dem typischen Bilde einer akuten gelben Leberatrophie nicht ohne weiteres gleichzusetzen, da die rein infiltrative Zellverfettung weit überwiegt gegenüber den Zerfallserscheinungen im Zentrum der Läppchen. Fragt man auch hier nach dem Zusammenhange zwischen Hyperemesis und Lebererkrankung, so muss anch hier die geringe Ausdehnung der Degenerationserscheinungen im Verhältnis zur langen Dauer des unstillbaren Erbrechens vor der Auffassung warnen, dass etwa die akute gelbe Leberatrophie der anatomische Ausdruck der Hyperemesis sei, vielmehr ist der Zellzerfall ganz frischen Datums, was auch aus dem späten Funde von Leuzin und Tyrosin folgt, obwohl sofort zu Beginn der schweren Krankheitserscheinungen darauf gefahndet wurde.

Zur Entscheidung der uns hier beschäftigenden Frage, können nur solche Beobachtungen verwertet werden, bei denen in völlig zweifelsfreier Weise, sowohl die klinischen Kriterien der Hyperemesis als auch die anatomischen der akuten gelben Leberatrophie vorhanden sind. Bei einer Durchsicht der obigen 13 Fälle zeigt sich, dass diese Bedingungen nur bei fünf von ihnen erfüllt sind. Es sind das die Beobachtungen von Hirschberg, Lang, Zaborsky, Williams und mir. Bei den übrigen handelt es sich 
entweder nur um eine akute gelbe Leberatrophie (Fall von Duncan, Fall von Beatty, ein Fall (III) von Ewing) oder um eine Form des Erbrechens, die von dem, was man allgemein unter Hyperemesis versteht, wesentlich abweicht (Fall von Stone und ein Fall (IV). von Ewing) oder endlich um Leberaffektionen, die dem Charakter einer akuten gelben Leberatrophie nicht entsprechen (2 Fälle (I, II) von Ewing, deren einer Eklampsieveränderungen und der andere eine Vergrösserung der verfetteten Iueber darbot). Im Falle Roughton's liegt überhaupt ein anatomischer Befund der Leber nicht vor.

Wie man sieht, ist eine genaue Begriffsbestimmung der hier in Frage kommenden Affektionen für die Klärung unserer Anschauungen über ihr gegenseitiges Verhältnis unbedingt erforderlich.

Bezüglich der Hyperemesis halten wir uns an diejenige Definition, die allgemein angenommen ist: Es handelt sich dabei um eine in der ersten Hälfte der Gravidität auftretende, immer über mehrere Wochen, oft über Monate sich erstreckende Affektion, die durch fortwährendes Erbrechen ausgezeichnet ist. Eine Organerkrankung, die mit Sicherheit als Ursache dieses Symptoms aufgefasst werden könnte, wird vermisst. Bisweilen findet sich Ikterus, oft auch geringe Mengen von Eiweiss; ersteres aber kann einfache Folge des sich einstellenden Inanitionszustandes sein, ist also für die Erklärung des Krankheitsbildes von zweifelhafter Bedeutung, und letzteres wird auch sonst oft in der Gravidität beobachtet. Es kommt allmählich zu einer hochgradigen Abmagerung und Schwäche der Patientin, trotzdem nimmt das Leiden in der überwiegenden Anzahi der Fälle einen günstigen Ausgang, indem das Erbrechen, sei es durch suggestive Behandlung, sei es durch therapeutische Eingriffe am Uterus, beseitigt wird. Wenn wir die Charaktere der Krankheit auf eine kurze Formel bringen wollen, so treten 3 Dinge in den Vordergrund: Ein wochen- und monatelang andauerndes, unstillbares Erbrechen, das zu hochgradiger Abmagerung und Schwächung des Körpers führt, ohne dass eine organische Ursache dafür auffindbar wäre.

Ein Fall wie der Stone's und Ewing's, der innerhalb weniger Tage unter dem Symptome des Erbrechens tödlich verlief, würde nach dieser Definition nicht in den Bereich der Hyperemesis fallen. Wegen einiger weniger in der Literatur auffindbaren Fälle von so akutem Verlauf, die Hyperemesis in akute und chronische Fälle zu teilen, wie es die amerikanischen Autoren wollen, halte ich 
nicht für berechtigt, so lange es noch nicht feststeht, dass beide auf dieselben Ursachen zurückzuführen sind. Bei den akuten ist die toxische Erklärung die einzig mögliche, bei den chronischen ist diese Aetiologie nicht zweifelsfrei und gerade das, was erst bewiesen werden soll. Das Erbrechen - auch das unaufhörliche kann an und für sich nicht die Zugehörigkeit zur Hyperemesis in sich schliessen, da es zweifellos auch unter anderen Bedingungen als den der Hyperemesis zugrunde liegenden auftreten kann.

Noch mehr gilt dieses von jenen Fällen, wo das Erbrechen überhaupt nur eines von vielen Symptomen bildet, die alsbald die Aufmerksamkeit auf ein bestimmtes organisches Lieiden hinlenken: Oefter handelt es sich dabei um Krankheiten, die mit der Gravidität gar nichts zu tun haben. So fand sich in einem Falle Zaborsky's (l. c.) ein Magenkarzinom, in einem Falle Flaischlens' eine Darmstenose. Manchmal handelt es sich aber auch um eine für den Zustand der Gravidität charakteristische Erkrankung der Leber, die akute gelbe Leberatrophie. Wenn sich, wie in dem Falle Duncan's und Beatty's alsbald Ikterus, Delirien, Benommenheit, motorische Unruhe und Zeichen einer schweren Nierenentzündung hinzugesellen, so sind das eben charakteristische Befunde der akuten gelben Leberatrophie, deren Vorkommen in der Gravidität längst bekannt ist. Man muss durchaus daran festhalten, diese Erkrankung als eine völlig selbstständige zu betrachten, die von Hause aus mit der gewöhnlich als Hyperemesis bezeichneten auch nicht das Geringste gemein hat. Sie kommt sowohl innerhalb wie ausserhalb der Gravidität, sowohl bei Männern wie bei Frauen und Kindern vor. Als Ursache wird allgemein eine Intoxikation angeschuldigt. Es bestehen gewaltige Unterschiede im klinisehen Verlaufe beider Krankheiten, wie schon aus dem Gesagten hervorgeht.

Daher muss es grosse Verwirrung hervorrufen, wenn Fälle, die von ihren Autoren selbst als akute Atrophie beschrieben worden sind, mit nachdrücklicher Verwahrung dagegen, dass es sich um eine Hyperemesis gehandelt haben könnte, von anderer Seite als Belege für eine toxische Form der Hyperemesis gravidarum angeführt werden, nur deshalb weil es einige wenige Fälle von Hyperemesis gibt, die in den letzten Lebenstagen die Symptome der akuten gelben Leberatrophie und bei der Sektion dieser ähn-

1) Zeitschr. f. Geburtsh. u. Gyn. Bd. 20. 
liche Befunde aufweisen. Dass diese aber eine andere Erkzärung, als sie der bezeichneten Auffassung entspricht, nicht nur zulassen, sondern in einzelnen Fällen sogar fordern, habe ich später zu zeigen.

Musste ich mich bisher gegen die in der Literatur beliebte allzu weite Auffassung der Hyperemesisbegriffes wenden, so ist dieses Verfahren auch hinsichtlich dessen, was wir unter "akuter gelber Leberatrophie" zu verstehen haben, angezeigt. Diese Affektion ist ein anatomisch scharf begrenzter Begriff. Wir verstehen darunter eine Verkleinerung des Organs infolge Nekrose oder fettiger Degeneration der Jueberzellen. Dieser Schwund des Leberparenchyms vollzieht sich sehr rasch, sodass von Tag zu Tag die Verkleinerung der Leberdämpfong verfolgt werden kann. Anatomisch kann man akute und chronische Formen mit all ihren Zwischenstufen unterscheiden. Zu Beginn, wo die Degenerationsprozesse vorherrschen, ist das äusserst weiche und morsche Parenchym von stark verwaschener Zeichnung, und infolge des erheblichen Organikterus gelb gefärbt. Mit dem völligen Zerfall des nekrotischen Zellmaterials tritt mehr die rote Farbe der entsprechend erweiterten Blutkapillaren hervor (rotes Stadium); diese Stellen sind auch der Sitz der alsbald eintretenden Bindegewebs- und Gallengangswucherung, die zusammen mit einer Neubildung von Leberzellen das Wesen der regeneratorischen Prozesse machen. Diese beginnen bereits sehr bald, sodass sie bei mehrere Wochen alten Fällen deutlich ausgebildet sind.

Wie wenig genau es manche Autoren mit der Nomenklatur nehmen, beweist Ewing. So beschreibt er eine Eklampsieleber von geradezu klassischem und für diese Erkrankung in seltener Weise typischem Aussehen unter dem Kapitel "akute gelbe Leberatrophie". Ich habe an anderer Stelle auseinander gesetzt ${ }^{1}$, dass beiden Krankheiten so gänzlich verschiedene anatomische Bilder zukommen, dass sie nimmermehr zusammengeworfen werden können. Ferner rechnet er eine verorösserte Fettleber, die histologisch allerdings die Zeichen des Zellzerfalls aufwies, auch zur akuten Atrophie. Ich halte auch das für verfehlt. Eine vergrösserte Leber kann man niemals als eine atrophische bezeichnen. Mir ist wobl bekannt, dass von einigen die Ansicht vertreten wird, dass im aller

1) Die anatomischen Lebererkrankungen in der Schwangerschaft. Zeitschrift f. Geb. u. Gyn. Bd. 70. 
ersten Stadium der akuten gelben Leberatrophie das Organ vergrössert sei. Das mag im Einzelfall zutreffen und sich auch beweisen lassen. Hier handelt es sich aber schon klinisch um einen durchaus nicht typischen Fall, den man meines Erachtens, um nichts zu präjudizieren, lediglich als Schwangerschaftsintoxikation bezeichnen dürfte. Auf all diese nicht in den Rahmen der bisher allgemein anerkannten Krankheitsbilder hineinpassenden Affektionen komme ich später noch einmal zurück.

Nachdem ich so die Notwendigkeit begründet habe, die Mehrzahl der von Williams beigebrachten Fälle als ungeeignet zur Entscheidung der Frage von den Beziehungen der akuten gelben Leberatrophie zur Hyperemesis gravidarum abzulehnen, gehe ich zur Besprechung der 5 Beobachtungen über, die einer Kritik standhalten.

Was zunächst die klinische Seite anlangt, so ist die geringste Krankheitsdauer 4 Wochen, die höchste 3 Monate, die übrigen währten 7,8 and 9 Wochen.

Das einförmige Bild des „unstillbaren Erbrechens" zeigt bisweilen einige Besonderheiten. So war in den Fällen von Hirschberg und Williams starker Speichelfluss vorhanden, in denen von Lang und mir bestand auch schon vor dem Eintritt der alarmierenden Erscheinungen und zwar wochenlang eine subikterische Färbung. Besondere Aufmerksamkeit verdient das Verhalten des Urins. Nur in einem Falle und zwar in dem von mir beigebrachten, war auch bereits im Stadium der blossen Hyperemesis eine geringe Eiweissausscheidung bemerkbar. Mehrfach fiel aber auch in diesem Ealle die Prüfung auf Albumen negativ aus, und Zylinder wurden während dieses Krankheitsstadiums nie gefunden. In allen übrigen Beobachtungen war bis zum Auftreten der schweren Symptome kein Eiweiss im Urin nachweisbar. Auf das Verhalten des Pulses bei den perniziösen Formen des Erbrechens ist namentlich von den französischen Autoren ein erheblicher Wert gelegt worden: Die Pulsfrequenz ist zu hoch im Verhältnis zur stets normalen Temperaturkurve. In meinem Falle betrug während der gesamten klinischen Beobachtungsdauer, die sich über einen Monat erstreckte, die Pulszahl stets über 120 und steigerte sich zu Zeiten seelischer Erregung bis zu 190 in der Minute. Diese ausgesprochene Tachykardie verliert aber an Beweiskraft durch die Angabe der Patientin, dass sie seit Jahren an beschleunigter Herztätigkeit leide. Sonst finde ich nur noch im Falle Lang's die Angabe, dass während 
der ganzen klinischen Beobachtungsdauer, die sich auch hier etwa über 1 Monat erstreckte, die Pulsfrequenz auf 120 in der Minute gesteigert war. In den übrigen Fällen war eine derartige hohe Frequenz im hyperemetischen Stadium der Krankheit nicht vorhanden. Die hier erwähnten besonderen Merkmale - bezüglich des Ikterus, der Eiweissausscheidung und der Pulsfrequenz - sind mithin so inkonstant, dass aus ihnen brauchbare Schlüsse auf den perniziösen Charakter dieser Formen von Hyperemesis nicht gezogen werden können.

Im allgemeinen geht das Krankheitsbild der einfachen Hyperemesis ziemlich plötzlich in das der akuten Atrophie über. Die Patientimen, die wohl bis dahin schwer unter dem fortwährenden Frbrechen gelitten hatten und dabei beträchtlich abgemagert sind - bei der meinigen ist der Gewichtsverlust während 1 Woche mit 5 Pfund notiert - werden mit einmal apathisch, somnolent, stärker ikterisch, unruhig, schreien, bekommen hohe Temperatur und hohen Puls und sterben in tiefem Koma. Die Dauer dieses von der akuten Atrophie her bekannten Zustandes hat in unsern Fällen $3,4,5,6$ und 8 Tage gewährt. Nur in einem Falle, in dem von Williams, fehlte der Ikterus. Da aber die Sektion ikterische Verfärbung der Organe nachwies, so ist wohl nur die ausserordentliche Kürze des letaten Krankheitsstadiums - es dauerte nur 3 Tage - die Ursache, dass der Gallenfarbstoff noch nicht bis in die Hant gedrungen war. Der Urin zeigt jetzt, wo daraufhin untersucht worden ist, meist Eiweiss und Zylinder. In meinem Falle konnte im eingedampften Sammelurin von 24 Stunden auch Leuzin und Tyrosin nachgewiesen werden, wovon in den anderen Beobachtungen nichts erwähnt wird. Durch das Auffinden dieser Körper ist auch der Schlussstein, dass es sich zum mindesten um eine der akuten gelben Leberatrophie sehr ähnliche Affektion in diesem Endstadium der Hyperemesis handelt, hinzugefügt.

Wie verhält es sich nun mit den anatomischen Befunden? Auch anatomisch liegt unzweifelhaft eine Atrophie vor. Die Leber, die sonst ein Gewicht von rund $1500 \mathrm{~g}$ hat, ist durehschnittlich $1000 \mathrm{~g}$ schwer, in einem Falle wiegt sie nur $750 \mathrm{~g}$. Die Schlaffheit ihres Gewebes, die verwaschene Zeichnung wird hervorgehoben. Aber der Grad der Lebererkrankung ist offenbar verschieden in den einzelnen Fällen, wie sich schon bei der Betrachtung mit blossem Auge kundgibt, und ebenso ist die Art und Ausdehnung der histologischen Läsionen nicht immer die gleiche. 
Was zunächst die makroskopischen Kriterien betrifft, so berichtet Hirschberg: Lebergewebe auffallend gelb und trübe, azinöser Bau eben wahrnehmbar, Zentren der Läppchen etwas dunkler und röter. Zaborsky (Entz) sagt von seinem Fall: Lebersubstanz schlaff, bröcklig, von mässigem Blutgehalt und teigiger Konsistenz, Schnittfläche gallig verfärbt, gelb mit einem Stich ins Grünliche, Läppchen klein, Zeichnung verschwommen. In der Mitte der Läppchen eine kleine bräunliche Vertiefung. Williams: Leber von gelber Farbe und weicher Konsistenz, auf dem Durchschnitt sehr fettreich und gallig imbibiert. Schon mit blossem Auge sind nekrotische degenerierte Bezirke sichtbar. Blutgefässe treten zwischen den gelbgefärbten Zellbalken deutlich hervor. Abgesehen davon, dass die Entartung nicht zu stark ist, erinnert sie doch sehr an das Aussehen der akuten gelben Leberatrophie. Nach meiner Beschreibung fand sich Folgendes: Die Leber ist von ockergelber Farbe, die besonders deutlich auf dem Durchschnitt hervortritt, Konsistenz leicht vermindert und etwas mürbe. Die Zeichnung der Leber ist sehr deutlich, da die Zentren der Läppchen durch ihre dunkelgrüne Färbung sich von der mehr hellen Parenchymfarbe des übrigen Lebergewebes deutlich abheben.

Das eine Mal ist also die Zeichnung der Leber ganz verschwommen, das andere Mal dagegen sehr deutlich, dazwischen finden sich Uebergänge. Meistens ist das Bild im Einzelfall ein gleichförmiges über die ganze Schnittfäche hin. Im Falle Williams aber traten deutlich nekrotische Bezirke hervor. Im ganzen ist der Eindruck für den Beobachter unzweifelhaft der einer akuten gelben Leberatrophie, so bei Hirschberg, Lang und Zaborsky, während Williams doch hervorzuheben genötigt ist, dass die Zerstörung doch offenbar nicht ganz so schwer ist, wie bei der gewöhnlichen Form der Krankheit. Was mich selbst anlangt, so lege ich, wenn ich den Fall unter die hier besprochenen einreihe, den Nachdruck auf die "Atrophie", deren degenerativer Charakter ohne weiteres ersichtlich war. Aber schon nach dem makroskopischen Bilde hätte ich, nachdem ich etwa $1 / 2$ Dutzend Fälle von typischer gelber Leberatrophie gesehen habe, beide Affektionen nicht für identisch erklärt. Es bestand offenbar in meinem Falle nur eine hochgradige Verfettung mit Ikterus und Atrophie. Was so charakteristisch für die akute gelbe Leberatrophie ist, die Lockerung der Balkenstruktur und die dadurch bedingte Verwaschung der Zeichnung war nirgends zu sehen. 
Im Anschluss hieran möchte ich auf eine weitere Abweichung von dem üblichen Bilde der akuten gelben Leberatrophie aufmerksam machen, auf das Fehlen einer Eigentümlichkeit, die zwar nicht notwendig zu dem anatomischen Bilde dieser Lebererkrankung gehört, die aber doch so häufig ist, dass die Tatsache, dass sie in allen hier beschriebenen Fällen vermisst wird, höchst bemerkenswert ist. Es ist hier immer nur von gelben, niemals von roten Partien die Rede; diese letzteren, die man seit Zenker als die weiter gediehenen, also früher zerstörten mithin älteren Degenerationsbezirke ansieht, fehlen vollkommen. Die Veränderung ist also immer eine sehr frische, und das deckt sich vollkommen mit der kurzen Dauer der schweren klinischen Erscheinungen, die, wie ich oben bemerkte, höchstens 8 Tage betrug. Die roten atrophischen Partien pflegen sich erst von der zweiten Woche der Krankheit ab vorzufinden, und da gewöhnlich erst um diese Zeit der Tod eintritt, so sind sie in fast allen Fällen anzutreffen.

Bei der histologischen Prüfung tritt diese Eigentümlichkeit der hier besprochenen Lebern noch deutlicher hervor. Hirschberg fand: "Verkleinerung der Acini und der einzelnen Elemente, die trabekuläre Anordnung der letzteren ist überall aufgehoben, sie liegen regellos durcheinander, Kerne sind wegen ihrer schwachen Färbbarkeit schwer zu erkennen, Protoplasma börnig getrübt, weist zahlreiche Fettröpfchen auf. In den Zentren der Läppchen starke Gallenfarbstoffablagerungen. Die interlobulären Bindegewebszüge sind mässig verbreitert, entsprechend der Verkleinerung der Acini, ebenso liegen die epithelhaltigen Gallenkanäle etwas dichter. " Der Autor, der zugleich über einen anderen Fall von akuter gelber Leberatrophie mit ausgesprochenen Regenerationserscheinungen berichtet und dessen Dauer auf ungefähr 5 Wochen berechnet, betont. diesem gegenüber die anfängliche Natur des bei dem Hyperemesisfalle angetroffenen Leidens, bei dem er.alle Zeichen einer Regeneration vermisst hat. Im Falle Lang's waren „die Leberzellen alle fettig degeneriert, die Fettröpfchen fliessen oft zu grösseren Tropfen zusammen, in einzelnen Zellen kann man noch einen schwach färbbaren Kern erkennen, meistens aber nicht. Alle Elemente zeigen eine starke Gallenfarbstoffablagerung." Auch hier sind somit die Zerfallserscheinungen noch ganz frisch. Beide Fälle haben das miteinander gemein, dass hier so gut wie alles Leberparenchym der Zerstörung anheimgefallen, also ein Befund, der 
für die typischen Fälle der akuten gelben Leberatrophie die Regel ist. Die nun folgenden 3 lassen dagegen im mikroskopischen Schnitt mehr oder minder grössere Bezirke, teils wohl erhaltenen, teils nur fettig infiltrierten Lebergewebes erkennen. Zunächst der: Fall Zaborsky: "Man kann gut erhaltene Leberzellen, die ihre trabekuläre Anordnung bewahrt haben, unterscheiden von anderen, die bei Verwendung von Kernfarbstoffen sehr hell erscheinen, fettigdegeneriert sind und im Zentrum der Läppchen liegen, während die erstgenannten Leberbezirke in der Umgebung der periportalen Bindegewebszüge gelegen sind." Worauf es hier ankommt, ist der für den Kundigen höchst auffällige Befund recht beträßchtlicher, der Zerstörung nicht anheim gefallener Gebiete. In der Leber von Williams kann man drei verschiedene Zonen im Läppchen unterscheiden: eine äusserste sehr schmale, in welcher die Zellen alle gut erhalten sind, daran schliesst sich nach innen eine fast die Hälfte des Läppchenradius einnehmende Schicht, in der die Zellen stark verfettet, der Kern sehwach färbbar ist und zuinnerst in unmittelbarer Umgebung der Zentralvene wird der Rest des Läppchens durch völlig nekrotische Leberzellen eingenommen, die gar keine Kernfärbung mehr annehmen und sich daher mit Eosin leuchtend rot färben. Nach der der Williams'schen Arbeit beigegebenen Abbildung finde ich, dass etwa das äussere Drittel des Läppchens noch eine gute Kernfärbung aufweist, also trotz der starken Fettinfiltration dieser Stellen nach der üblichen Auffassung keineswegs als degeneriert und irreparabel geschädigt anzusehen ist. Also auch hier ist ein bemerkenswerter Rest der Zellen noch erhalten. Noch stärker tritt diese Eigentümlichkeit in der von mir beschriebenen Leber zu Tage. Das ganze Lebergewebe war wohl stark verfettet, aber die weitaus grösste Mehrzahl der Zellen trägt lediglich den Charakter der von der vulgären Fettleber bekannten Elemente, das heisst, sie sind nicht zerfallen, der Kern an die Wand gedrängt und gut färbbar. Lediglich in der Umgebung der Zentralvene, also in einem Bezirke, der an Ausdehnung nur einen geringen Teil der Masse des Gesamtläppchens beträgt, waren die Zellen im Zerfall begriffen. Hier bestand auch Gallenstaung und ikterische Pigmentierung der Elemente, von Regenerationsbildern war auch nieht die geringste Andeutung zu sehen.

Vergleicht man diese 3 Lebern in histologischer Beziehung: miteinander, so fällt zunächst auf, dass stets die zentral gelegenen Zellen am schwersten geschädigt sind. Im Falle Zaborsky's und 
meinem geht der Zellschwund fast ausschliesslich auf dem Wege der Zellverfettung vor sich, bei Williams dagegen tritt die zentrale Nekrose der Zellen in den Vordergrund. Diesen Unterschieden hat Paltauf eine gewisse Bedeutung beigemessen und nur die letzte Form als genuine Atrophie bezeichnet. Die erstere Form des Zellschwundes ist auch von Paltauf beobachtet worden und zwar bei Vergiftung mit Ammanita phalloides. Es ist bemerkenswert, dass dieser Autor bei einer 14 Tage alten derartigen Vergiftung schon deutliche Regenerationserscheinungen wabrgenommen hat.

Weitere Unterschiede beziehen sich auf die Form und Lokalisation der Fettablagerung. Bei Williams war das Fett in kleinen Tropfen (von der Grösse der Zellkerne) und am stärksten in der intermediären Zone vorhanden. In meinem Falle war gerade diese Zone relativ fettfrei, war hier allerdings von kleintropfigem Charakter, während im Zentrum und in der Peripherie das Protoplasma ron grossen Tropfen infiltriert war. Bei Zaborsky beschränkte sich die Verfettung lediglich auf die zentroazinäre Zone, die peripheren Zonen waren hier fettfrei. Hier liegen bei ihm und Williams die besterhaltenen Zellen, während sie bei meinem Falle in der intermediären Zone gelegen sind.

Sehen wir nun auch mit Kretz das Endprodukt; die degenerative Atrophie, als das ausschlaggebende Moment an, das uns dazu führt, all diese Erkrankungen trotz mancher histologischer Differenzen unter einem einheitlichen Gesichtspunkte zusammenzufassen, so dürfen wir doch nicht vergessen, dass das gleiche Ziel auf verschiedenen Wegen erreicht wird, und dass der Umfang der Zerstörung ein sehr verschiedener ist. Dabei tragen aber doch die sich darbietenden anatomischen Veränderungen in allen Fällen die Charaktere der Frühformen der akuten gelben Leberatrophie. Die Beobachtungen von Hirschberg und Lang zeigen die schweren, dem typischen Bilde entsprechenden Veränderungen des Gesamtparenchyms, aber in einem so frühen Stadium der Erkrankung, dass rote eingesunkene Partien überhaupt nicht vorhanden waren, und auch bei der histologischen Untersuchung die sie bedingenden hyperämischen Strecken und alle Regenerationserscheinungen völlig vermisst wurden. In den 3 übrigen Fällen sind mehr oder minder ansehnliche Gebiete überhaupt nicht der Zerstörung anheimgefallen und diese teils in völlig normalem Zustande, teils im Stadium hochgradiger Fettinfiltration.

Die Tatsache, dass die hier vorliegenden Fälle von akuter 
gelber Leberatrophie alle frische und wenig fortgeschrittene Formen aufweisen, wirft nun ein scharfes Licht auf die Beziehungen dieser Erkrankung zur Hyperemesis gravidarum. Wer sich erinnert, dass die akute gelbe Leberatrophie schon im Verlaufe weniger Tage die schwersten Zerstörungen des Organs bedingt, und damit vergleicht, dass die Hyperemesis auch bei monatelanger Dauer so ausgesprochene Veränderungen nicht hervorzubringen vermag. oder gar nur partielle Zerstörungen des Organs mit sich führt, der erkennt, dass es nicht zulässig ist, diese Fälle von Hyperemesis nur für eine besondere klinische Form der akuten gelben Leberatrophie zu balten. Wären sie das, so müssten jene seltenen anatomischen Bilder subakuter und chronischer gelber Atrophie resultieren, die mit deutlichen Regenerationserscheinungen einhergehen und eben dadurch ihr dem längeren Bestande der Hyperemesis entsprechendes höheres Alter bekunden würden. Solche Fälle sind aber bisher nicht bekannt geworden, und damit fehlen auch wirklich vollgültige anatomische Zeugnisse für den toxischen Ursprung dieser Fälle von Hyperemesis.

Auf Grund der oben gebrachten Nachweise kann man das Verhältnis der Hyperemesis zur akuten gelben Leberatrophie nur so auffassen, dass sich an ein unstillbares Erbrechen eine akute gelbe Leberatrophie angeschlossen habe, die oft von so kurzer Daner ist, dass sich sowohl die klinischen wie die anatomischen Zustände nicht in typischer Weise entwickeln können. Letzteres aber wird dadurch bedingt, dass der sehon durch die Hyperemesis stark geschwächte Organismus der der akuten gelben Leberatrophie zugrunde liegenden Intoxikation zu rasch erliegt.

Fassen wir nun die in anderen Fällen bei den Sektionen an Hyperemesis Verstorbener erhobenen Befunde ins Auge, so begegnen wir zunächst. solchen, die eine gewisse Aehnlichkeit mit den eben besprochenen haben. Ihr charakteristisches Merkmal ist auch eine Leberveränderung, nur dass diese nicht zur Atrophie des Organs geführt hat. Hierher gehört zuerst der Fall von SolowieffLindemann (Zentralbl. f. Gynäkol. 1902. S. 492 und Zentralbl. f. Patholog., Bd. III).

5 Wochen nach dem Zessieren der Menses Beginn des Erbrechens, das so heftig wurde, dass man zur rektalen Ernährung schreiten musste. Aufnahme in die Klinik am 1. I., nachdem das Erbrechen 6 Wochen bestanden hatte. Status: Grosse Schwäche und Abmagerung, Puls klein, 
frequent, 130, Magenschmerzen, Uebelkeit, häufiges Erbrechen. Urin enthält Spuren von Eiweiss, die jedoch später nicht mehr gefunden werden, ebensowenig andere Zeichen einer Nephritis. Harnsäuremenge ist vermehrt, während die Harnstoffausscheidung herabgesetzt ist.

Durch neurologische Untersuchung wird eine Hysterie festgestellt, für die auch in der persőnlichen wie in der familiären Anamnese gute Gründe vorliegen. Dementsprechend wird durch elektrische und hypnotische Behandlung eine Besserung des Zustandes erzielt, insofern das. Erbrechen weniger stark auftrat, der Schlaf besser wurde und der Puls auf 100 herabging. Jedoch stellte sich nunmehr eine Polyneuritis ein, deren Ursache nicht in einem Alkoholismus gesehen werden konnte, und daher auf ein "während der Hyperemesis produziertes Toxin" zurückgeführt wurde. Die Kranke wird immer schwächer, das Bewusstsein verdunkelte sich, Delirien stellten sich ein, Puls ging auf 160, so erfolgte der Tod am 20. I.

Bei der Sektion fand man das Herz dilatiert, Herzfleisch weich, leicht zerreisslich. Im Magen an der Kardia einige Ekchymosen. Die Leber von normaler Grösse, ihr seröser Ueberzug unverändert, sie ist im ganzen lehmfarben und hat stellenweise Flecken, die für die Degeneration der Substanz sprechen. Nieren: Oberfläche glatt, auch hier auf dem. Durchschnitt matt gefärbte Stellen (Nekrose?). Papillen blass.

Die mikroskopische Untersuchung der Leber zeigt eine ausgeprägte Verfettung, Kerne der Leberzellen sind erhalten, es werden keine nekrotischen und zerfallenen Zellen angetroffen. Die mit Hämatoxylin tiefblau gefärbten Kerne sind wenig regelmässig verteilt. In der Nähe grösserer Gefässe findet sich Anhäufung von Kernen. Die Gallenkapillaren sind hier und da von körnigen gelben Massen ausgefülltt.

Die mikroskopische Untersuchung der Niere zeigt völlige Unversehrtheit der Malpighi'schen Körperchen, dagegen sind die Epithelien der gewundenen Harnkanälchen in allen Stadien der Degeneration: trübe Schwellung, fettige Degeneration, Koagulationsnekrose. Die Lumina der Harnkanälchen sind durch nekrotische, von der Membrana propria abgelöste Massen verschlossen, die geraden Harnkanälchen sind in ihrer Mehrzahl gut erhalten, nur einzelne Strecken gleichfalls degeneriert und nekrotisch, vereinzelt findet man auch Blut.

Die mikroskopische Untersuchung vom Phrenicus und Vagus ergab gleichfalls Zeichen der Degeneration.

Der zweite hierhergehörige ausführlich beschriebene Fall stammt. von Winter-Hofbauer (Monatsschr. f. Geburtsh. u. Gynäkol. Bd.25. S. 751 und Zeitschr. f. Geburtsh. u. Gynäkol. Bd. 61. S. 262).

Die Krankengeschichte ist nur kurz behandelt. Winter hebt hervor, dass seine Patientin wochenlang das Bild einer einfachen Hyperemesis mit all ihren charakteristischen Schwankungen dargeboten hatte, bis plötzlich hohes Fieber, Nephritis, Krämpfe und hohe Pulsfrequenz auftraten, Erscheinungen, unter denen die Kranke innerhalb kurzer Zeit zugrunde ging.

Die Obduktion ergab folgenden Befund:

Die Leber überragt den Rippenrand, Rinde etwas gewulstet, auf dem Durchschnitt erscheint das Gewebe gleichmässig hell grau mit einem deutlichen Stich ins Gelbliche, an den Rändern kleine Ekchymosen.

Die Nieren von gewöhnlicher Grösse, auf der Schnittfäche ist die Rindensubstanz stellenweise leicht gelblich gefärbt. 
Zahlreiche Ekchymosen in der Schleimhaut des Magens und Darmes und im Endokard des linken Ventrikels.

Die mikroskopische Untersuchung ergab folgendes: An der Peripherie der Leberläppchen erscheint zunächst die Zellgrenze undeutlich und verschwommen, so dass stellenweise die Zellkerne in regelmässigen Abständen in ein gleichartiges, an ein Synzytium erinnerndes Lager eingetragen erscheinen. Dabei ist das Zellplasma feinkörnig oder auch vakuolär entartet, wobei besonders zu betonen ist, dass diese Vakuolisierung und Rarefizierung des Zellplasmas auch an Präparaten kenntlich ist, welche nicht mit Fett extrahierenden Mitteln behandelt worden war. Die Kerne sind grösstenteils noch gut erhalten, stellenweise aber ist das Kerngerüst kaum gefärbt und vereinzelte Kerne wiederum sind pyknotisch. Das Zentrum der Leberazini zeigt ein wesentlich anderes Bild. Hier sind die Leberelemente in typische Fettzellen umgewandelt und die Kerne an die Wand gedrängt; so erhält das Ganze ein marmoriertes Aussehen, dadurch, dass die Mitte der Läppchen als heller Fleck erscheint, der von einer dunkler gefärbten Randzone rumgeben ist.

Die mikroskopische Untersuchung der Nieren ergab schwere Veränderungen an den Epithelien der Tubuli contorti und zwar Vakuolisierung des Protoplasmas, mangelhafte Kernfärbung bis zu völligem Kernschwund, starke feinsttropfige Verfettung und Ausfüllung ihres Lumens mit einer geronnenen strukturlosen Masse.

Ich beschränke mich hier auf die Mitteilung dieser beiden Fälle, weil die übrigen von Williams hinzugerechneten Beobachtungen mir, was die Deutung der Leberveränderungen anlangt, nicht einwandsfrei erscheinen, da komplizierende Erkrankungen im Spiele sind, welche an und für sich ähnliche Veränderungen hervorbringen.

Werfen wir einen Rückblick auf diese letzteren, so nehmen wir wiederum eine starke Verfettung der Leber wahr, die in dem ersten Falle den Charakter der reinen Fettinfiltration hat, während in dem zweiten zugleich degenerative Veränderungen angetroffen wurden. Letztere spielen sich in der Peripherie der Leberläppchen ab und bestehen in unscharfer Begrenzung der Zellen, Vakuolisierung des Protoplasmas, die nicht auf Fettextraktion beruht und Pyknose der Kerne. Hofbauer spricht daher bezüglich der Randzone des Läppchens von einer "parenchymatösen Hepatitis", während in den Zentren reine Fettinfiltration von grosstropfigem Charakter vorherrscht.

Die peripheren Zelldegenerationen sind entschieden seltener als die zentralen, denen wir ja in den oben besprochenen, zugleich atrophischen Lebern vorzugsweise begegneten, immerhin steht diese Beobachtung nicht vereinzelt da, wie der Fall Stone's (S. 564) zeigt. 
Fragen wir nach der Ursache dieser Veränderungen, so können wir schon aus dem gleichzeitigen Vorkommen schwerer Parenchymdegenerationen an den Nieren auf ihren toxischen Ursprung schliessen, da eine Infektion nicht nachweisbar war. So einleuchtend auch diese Deutung ist, so muss doch hervorgehoben werden, dass auch eine andere Aetiologie hier in Frage gezogen werden kann. Schon Lindemann (l. c.) hat auf die Möglichkeit hingewiesen, dass hier Folgen des Inanitionszustandes vorliegen könnten, und zwar kommen hier meines Erachtens zwei Momente in Betracht. Zunächst der Hungerzustand an sich, dann aber auch, beim Menschen wenigstens, mit einem solchen verbundene charakteristische Anomalien des Stoffwechsels.

Der Einfluss des Hungerns auf die Organe ist experimentell besonders von russischen Autoren ${ }^{1}$ ) studiert worden. Es wurden Degenerationen fast aller wichtigen Organe beschrieben, insbesondere auch Verfettung der Leber und Nieren. Später wurden diese Resultate in mehr kritischer Weise behandelt und gefunden, dass bei den untersuchten Tierarten auch normalerweise die beschriebenen Verfettungen und Kernanomalien vorkommen, und so schliesslich jeder Einfluss des Hangerns nach der bezeichneten Richtung geleugnet [Lazarew ${ }^{2}$ ), Traina ${ }^{3}$ )]. Aus der menschlichen Pathologie liegen uns gleichfalls keine sicheren Beweise für degenerative Organveränderungen infolge von Inanition vor. Weder beim Hungertode aus selbstmörderischer Absicht, noch als Resultat eines Verschlusses der Nahrungswege ${ }^{4}$ ) sind Degenerationen von Leber und Nieren beobachtet worden. Jeder Pathologe hat oft Gelegenheit Sektionen von Leichen zu machen, die aus irgendwelcher Ursache (z. B. Magencarcinom) hochgradig abgemagert sind, wo so gut wie das gesamte Fettpolster geschwunden ist; hier hat also die Abmagerung noch viel höhere Grade erreicht als gewöhnlich bei der Hyperemesis, bei der in fast allen Sektionsprotokollen betont wird, dass das subkutane Fett der Bauchhaut manchmal sogar noch in ansehnlicher Menge vorhanden war. Trotzdem entsprechen die in solchen Fällen beobachteten Organveränderungen lediglich der allgemeinen Atrophie des Körpers und bieten - be-

1) S. Mühlmann, Ref. über die Pathologie des Hungerns. Zentralbl. f. Pathol. Bd. 10 .

2) S. bei Mühlmann.

3) Ziegler's Beitr. Bd. 35 .

4) Puppe in Schmidtmann's Handbuch der gerichtlichen Medizin. 
sondere Ausnahmefälle, die eine andere Beurteilung verlangen, abgerechnet - keine Organveränderungen dar, die man mit denen aus toxischer Ursache entstandenen verwechseln könnte.

Ausser der Inanition an sich, kommen aber als mögliche Quelle der beschriebenen Läsionen gewisse Stoffe in Betracht, die sich beim Menschen infolge ungenügender Ernährung, insbesondere bei Kohlehydratkarenz im Körper bilden, nämlich die Azetonkörper (Oxybuttersäure, Azetessigsäure, Azeton). Sie werden beim Hungern schon in den ersten Tagen ausgeschieden und sind demgemäss bei der Hyperemesis häufig aufgefunden worden. Was die Giftwirkung dieser Stoffe anlangt, so muss man unterscheiden zwischen den durch Tierversuche gewonnenen und den durch Beobachtung am kranken Menschen gefundenen Tatsachen. Wenn Trambusti and Nesti ${ }^{1}$ ) Tiere mit Phloridzin vergifteten, so konnten sie nachweisen, dass, sobald eine stärkere Azetonurie auftrat, auch schwere Parenchymdegenerationen da waren, und Albertoni2) gelang es mit hohen Azetongaben schwere Nekrosen des Epithels der gewundenen Harnkanälchen hervorzurufen. Demgegenüber schätzt $\mathrm{Naunyn}{ }^{3}$ ) die Giftigkeit des Azetons nur sehr gering ein, da er wochenlang Diabetiker grosse Mengen dieses Stoffes ausscheiden sah, ohne dass Erscheinungen einer Intoxikation oder Albuminurie vorlagen. Ich glaube, dass diese Erfahrungen mehr ins Gewicht fallen, als die durch experimentelle Vergiftungen erzielten Resultate, die durch eine willkürlich hoch gewählte Dosis des Giftes herbeigeführt wurden und bei denen übrigens die Leber auch gar keine auffälligen Veränderungen darbot.

Hiernach halte ich es für unerwiesen, dass die bei diesen beiden Fällen von Hyperemesis vorgefundenen Veränderungen von Leber und Niere durch die Inanition verschuldet seien, und sehe mich auch hier zu der Annahme genötigt, eine spezifische Schwangerschaftsintoxikation als Ursache anzusehen. Diese Annahme liegt um so näher, als die erwähnten Befunde als Vorstufe der mit Atrophie verknüpften betrachtet werden müssen, deren Quelle ja nur in der bezeichneten Richtung gesucht werden kann.

Es liegt hier also ein früheres Stadium der Leberveränderung vor als das, welches wir oben kennen gelernt haben, insofern ein

1) Liegler's Beitr. Bd. 6.

2) Zitiert nach Trambusti und Nesti.

3) „Diabetes" in Nothnagel's Handbuch. 
Zerfall der Lebersubstanz noch nicht eingetreten ist. Fragen wir auch hier nach dem Alter des Prozesses, so ist die Möglichkeit dieses zu bestimmen, offenbar nur gegeben durch den Vergleich mit solchen Intoxikationen, die bei ähnlichen anatomischen Veränderungen eine genaue Feststellung des Beginns der Vergiftung gestatten. Naturgemäss ist dies nur bei äusseren Vergiftungen der Fall. Von diesen ist die Vergiftung mit Phosphor oder mit Pilzschwämmen eine solche, die in ganz ähnlicher Weise wie die hier besprochenen durch ein Stadium der einfachen Leberverfettung zur Leberatrophie führt. Die Verfettung entwickelt sich in diesen Fällen überraschend schnell, so dass man schon nach wenigen Stunden oder Tagen eine ausgesprochene Fettleber vorfindet, und bereits in der zweiten Woche nach der Einführung des Giftes ist die Atrophie eine sehr ausgesprochene. Wenn man diese Erfahrung auf unsere Fälle überträgt, so würden die bei der Hyperemesis beobachteten Veränderungen erst wenige Tage alt sein, und das würde auch gut übereinstimmen mit den klinischen Daten des Winter'schen Falles, der erst kurze Zeit vor dem Tode plötzlich auftretende Intoxikationserscheinungen dargeboten hatte. Auch hier würde also ganz ähnlich wie bei den mit Atrophie einhergehenden Leberveränderungen das Alter der pathologisch-anatomischen Befunde für eine wesentlich kürzere Dauer der Intoxikation sprechen, als mit der Annahme eines toxischen Ursprungs der Hyperemesis vereinbar ist. -

Während in allen bisher angeführten Beobachtungen immer nur von diffusen Leberveränderungen berichtet wird, zeigt die folgende, dass in sehr seitenen Fällen auch herdförmige Läsionen, wie wir sie von der Eklampsie her kennen, angetroffen werden.

Champetier de Ribes et Bouffe de St. Blaise ${ }^{1}$ ), Note sur un cas de romissements incoereibles avec autopsie. Comptes rendus de la soc. de gyn., d'obstr. et péd. de Paris. 1901. p. 111, 195 .

IV para, im 6. Monat schwanger, leidet seit 15 Tagen an hartnäckigem Erbrechen. Sie war beträchtlich abgemagert, ohne dass die physikalisehe Untersuchung der Organe irgendeine Abweichung von der Norm nachweisen konnte. Puls 100. Sie verliess das Hospital gegen ärztlichen Rat, kehrte aber in etwa 3 Wochen wieder und wurde spontan entbunden. Das Brechen liess nach, aber ihr Befinden wurde schlechter. Zunge trocken. Puls wurde schneller, sie bekam Delirien und Krämpfe

1) Bericht nach der Arbeit Stone's, 1. c. S. 7. 
und starb 17 Tage nach der Entbindung. Der Urin enthielt eine reichliche Menge Eiweiss.

Die Sektion zeigte, dass Gehirn, Herz und Lungen normal waren. Die Nieren boten das Bild der parenchymatösen Nephritis. Die Leber wog $1370 \mathrm{~g}$, war von blassem Aussehen mit gelben Flecken. An ihrer Unterfläche war ein schwärzlicher Bezirk von Nussgrösse und harter und fester Konsistenz. Es handelt sich um einen alten (?) Infarkt, der von nekrotischem Lebergewebe eingenommen war. Am unteren Leberrande findet sich ein hämorrhagischer Bezirk von $5 \mathrm{gcm}$ Umfang, hier sind auch zahlreiche kleine Blutextravasate.

Die Autoren identifizieren diese Veränderungen mit denen, die bei der Eklampsie gefunden werden. Nach dem makroskopischen Aussehen ist die Aehnlichkeit unverkennbar; leider hat, wie auch Williams bedauert, eine Veröffentlichung der mikroskopischen Befunde nicht stattgefunden, so dass über die Natur und das Alter der einzelnen Veränderungen ein sicheres Urteil nicht möglich ist. Lassen wir diese Befunde nun als eklamptische gelten, so haben wir hier eine etwa 5 Wochen lang dauernde Hyperemesis vor uns, die nach der Entbindung in eine Eklampsie überging. Dass schon die vor der Entbindung aufgetretenen Symptome auf die Eklampsie zu beziehen sind, ist nach dem klinischen Verhalten nicht anzunehmen.

Zweifelhaft ist nur, wie die Beziehung beider Erkrankungen zueinander zu denken ist. Entweder sind sie völlig unabhängig voneinander, und die Eklampsie ist rein zufällig bei einer Frau aufgetreten, die früher an Hyperemesis gelitten hat. Oder die Eklampsie bildet, ähnlich wie in den früheren Fällen die akute gelbe Leberatrophie, das toxische Endstadium der Hyperemesis.

Dieses ist leider nicht mit Sicherheit zu entscheiden. Träfe aber die letztere Annahme zu, so würde auch diese Beobachtung zeigen, dass die Intoxikation erst nachträglich zur Hyperemesis hinzutritt. -

Treten, wie sich aus diesem Ueberblick ergibt, nun auch die Leberaffektionen entschieden an Bedeutung hervor, so haben wir doch schon bei den letzt besprochenen Beobachtungen den Nierenveränderungen einen wichtigen Anteil an dem pathologischanatomischen Bilde einräumen und sie zur Klärung der Sektionsbefunde verwerten müssen. Es gibt nun aber seltene Fälle, in denen diese letzteren so überwiegen, dass sie schliesslich dem Krankheitsbilde ihren Stempel aufdrücken können. Hier möchte ich eine Beobachtung von Erismann anführen (Beiträge zur Lehre der Hyperemesis gravidarum. Inaug.-Diss. Basel 1890): 
26 jährige II para, letzte Regel 8. IX. 1889. Im September und Oktober litt die Patientin öfter an Erbrechen. Mit Anfang November steigerte sich dasselbe noch, so dass, zunächst sowohl auf nüchternen Magen wie auch nach Aufnahme von Speisen, und schliesslich ganz unabhängig hiervon, selbst in der Nacht erbrochen wurde. Infolge davon starke Abmagerung und allgemeine Schwäche. Diese fand sich bei der Aufnahme am 11. I. deutlich ausgeprägt. Puls 126. Im klar gelassenen Urin zeigt sich nach dem Aufkochen auf Zusatz von Salpetersäure eine leichte Trübung. Pat. erhält Nährklystiere. 15. I. Temp. 36,5, Puls 124. Urin dunkelbrawnrot, enthält massenhaft unveränderte rote Blutkörperchen and $1 \mathrm{pM}$. Eiweiss. Urinmenge in 24 Stunden $410 \mathrm{ccm}$. $\mathrm{Am}$ 16. I. Temp. 36,8, Puls 136, regelmässig, voll. Pat, hat nicht mehr gebrochen, Zunge sehr trocken, bräunlich, Schwindelgefühl, Kranke kann die Finger nur auf $35 \mathrm{~cm}$ Entfernung zählen, die Personen in der Umgebung erscheinen ihr als blosse Schatten. Rechte Nierengegend empfindlich, im Urin bedeutend weniger rote Blutkörperchen, einige hyaline sowie epitheliale Zylinder, weniger Eiweiss, Urinmenge $520 \mathrm{ccm}$. Die ophthalmoskopische Untersuchung weist beiderseits retinale Blutungen nach. 17. I. Temp. 37,1, Puls 120. Pat. hat einmal beim Husten erbrochen, Schwindelgefühl, Urinmenge $750 \mathrm{ccm}$. 18. I. Temp. 36,2, Puls 132, keine Kopfschmerzen, aber immer noch Schwindel. 19. I. Auf beiden Lungen unbestimmtes Atmen und Rasselgeräuseh. Leberdämpfung normal. Urin wird nicht spontan gelassen. Temp. 37,3, Puls 144. Kampferinjektion. 20. I. Exitus.

Sektionsbefund (Prof. Roth): Haut bräunlich, Conjunctiva bulbi leicht gelblich. Panniculus adiposus noch erhalten. Muskulatur des linken Ventrikels schmutzig-gelbbräunlich. Mikroskopisch finden sich hier zahlreiche Fasern in feinkörniger Fettdegeneration. Der linke Unterlappen ist verdichtet. Linke Niere vergrössert, Kapsel überall festsitzend, doch ohne Substanzverlust trennbar. Nierenoberfläche ganz glatt, mit kleinen Gefässsternen besetzt. Rindensubstanz $6 \mathrm{~mm}$ breit, helibräunlich trüb, Marksubstanz bräunlichrot, Konsistenz ziemlich fest, die aufsteigenden Arterien gefiillt, vereinzelte punktförmige Blutextravasate. Mikroskopisch starke Trübung, beginnende Fettdegeneration der gewundenen Kanälchen, in einzelnen stecken braune körnige Schollen. Rechte Niere vergrössert, blutreicher als dio linke. An der Oberfläche der trüben, schmutzig-gelben Rindensubstanz einzelne punktförmige Blutextravasate. Im Nierenbecken bräunlicher Harn mit flockigem Sediment. Mikroskopisch zahlreiche rote Blutkörperchen und braune, eckige Klümpchen. Beide Nieren $360 \mathrm{~g}$ schwer. Magen: An der hinteren. Wand punktförmige Blutungen, an der grossen Kurvatur drei stecknadelkopfgrosse Erosionen mit rotem Hof. An der Vorderwand einige kleinere hämorrhagische Erosionen. Leber: Blass, gelbrötlich, Konsistenz normal, auf dem Durchschnitt schmutzig-graugelb, $1950 \mathrm{~g}$ schwer. Beide Bulbi zeigen kleine Blutergüsse.

Die anatomische Diagnose lautet somit: Nephritis parenchymatosa haemorrhagica. Degeneratio cordis adiposa. Hypostase und Splenisation der Lange. Fettleher. Chronischer Milztumor. Hämorrhagische Erosionen des Magens. Retinitis haemorrhagica duplex. Hydrocephalus internus und externus.

In diesem Fall tritt also die Nephritis sowohl anatomisch wie klinisch durchaus in den Vordergrund, dabei sind die anatomischen 
Veränderungen der Niere ganz frischen Datums, so dass der Autor sich über das Verhältnis der Nierenerkrankung zur Hyperemesis so ausdrückt:

"Die parenchymatöse hämorrhagische Nephritis, welche am 5. Tage nach dem Eintritt der Patientin in das Spital deutliche Erscheinungen ihres Bestehens machte, bleibt betreffs der Entstehungsweise unklar. Anamnestische Anhaltspunkte für die Aetiologie der Nephritis liessen sich bei der Patientin nicht eruieren, und ein ursächliches Moment zur Erklärung ihrer Genese in den ersten Tagen des Spitalaufenthaltes konnte ebenfalls nicht nachgewiesen werden. So viel aber ist wohl sicher, dass durch die schon während längerer Zeit bestandene Hyperemesis ein überaus günstiger Boden geschaffen war für die Entwicklung dieser weiteren Komplikationen ${ }^{1}$ ) der Schwangerschaft. Infolge der allgemeinen schweren Ernährungsstörungen, welche das übermässige Erbrechen bei der ohnehin anämischen Patientin gesetzt hatte, konnten die ebenfalls weniger widerstandsfähig gewordenen Nieren, so kann man sich denken, gegenüber einem vielleicht an sich unbedeutenden äusseren, entzündungserregenden Agens nur in ungenügender Weise reagieren, so dass eben die geringste, unserer Aufmerksamkeit leicht entgangene Schädlichkeit zur vollen Geltung zu gelangen, die schwere Nephritis zu erzeugen vermochte.

Die Nephritis selbst in ätiologischen Zusammenhang mit der Hyperemesis zu bringen, dürfte mit Rücksicht auf den frischen Krankheitsprozess, wie er in den Nieren post mortem gefunden wurde, wohl nicht angehen ${ }^{1}$; zweifellos dagegen kann, wie hervorgehoben, die Hyperemesis als bedeutungsvolles prädisponierendes Moment für die Entwicklung. der komplizierenden Nephritis angesehen werden."

Der Verfasser kommt also bezüglich der Nierenveränderungen und ihres Verhältnisses zur Hyperemesis zu dem gleichen Resultat wie ich hinsichtlich der beobachteten Leberaffektionen. Ich teile auch in bezug auf diesen Fall völlig seine Ansicht und möchte nur, was die Ursache der Nierenerkrankung anlangt, nicht wie er, von aussen kommende Schädlichkeiten anschuldigen, wofür ja auch gar kein Anhaltspunkt vorliegt, sondern endogene Noxen in dem

1) Im Original nicht gesperrt gedrackt. 
Sinne, wie ich das in Uebereinstimmung mit modernen Anschauungen schon öfter hervorgehoben habe.

Weit schwieriger gestaltet sich die Beurteilung eines anderen von demselben Verfasser mitgeteilten Falles, der gleichfalls bei der Obduktion Nierenveränderungen, aber von sehr komplizierter Art dar'geboten hatte.

Es handelte sich um eine 22 jährige Ipara, die in ihrem 13. Lebensjahre einen Abdominaltyphus durchgemacht hatte und sonst nie krank gewesen war. Letzte Regel im Juli 1889. Aufnahme in die Klinik am 17. I. 1890. In den ersten 3 Monaten der Schwangerschaft litt Pat. an starkem Erbrechen, seit 2 Monaten erfolgte das Erbrechen nach jeder Speiseaufnahme, auch ohne solche des Nachts, sie hat in den letzten 9 Wochen das Bett hüten müssen. Regelung der Diät und medikamentöse Behandlung ohne Erfolg. Die inneren Organe erweisen sich bei der Untersuchung als normal. Man schreitet zur rektalen Ernährung. Am Tage der Aufnahme Temperatursteigerung bis 39,3, Puls bis 160. Am folgenden Tage und in den nächsten paar Wochen hält sich die Temperatur auf normaler Höhe. Im Urin findet man anfänglich sehr viel rote Blutkörperchen, angeblich aber kein Eiweiss, ebenso wenig Zylinder. In der Folgezeit macht sich eine ikterische Färbung der Skleren und der Haut bemerkbar, im Urin erscheint Gallenfarbstoff, Blutkörperchen nur noch spärlich, niemals Eiweiss oder Zylinder. Der Puls aber bleibt dauernd hoch, zwischen 100 und 130, das Erbrechen wird allmählich geringer; jedoch hält diese Besserung nicht an, und da seit mehreren Tagen das Erbrechen wieder heftiger auftritt und der Kräfteverfall vorwärts schreitet, so wird am 10. II. die künstliche Frühgeburt mittels Scheidentamponade eingeleitet. Am 13. II. Muttermund fünfmarkstückgross, die Erweiterung geht nur langsam vorwärts, Temperatur steigt von morgens 38,5 bis 39, 7 am Abend, so dass man sich zur Perforation entschliesst. Manuelle Lösung der Plazenta. 14. II. Temp. 33,2 (?), Puls 140, fortwährendes Erbrechen, Klysmen werden nicht gehalten, Kampferinjektion, abends Temp. 36, Puls 128. Am folgenden Tage grosse Schwäche, Temp. 36,4, Puls 128, abends Exitus.

Sektion (Prof. Roth): Herzmuskulatur blass, vereinzelte subseröse Ekchymosen, kleine Blutungen auch im rechten Unterlappen.

Linke Niere vergrössert, Kapsel lässt sich schwerer abziehen als normal, Oberfläche narbig eingezogen. Die Narben hirsekorn- bis kleinbohnengross, sind im unteren vorderen Drittel schiefrig. Die Rindensubstanz trüb, schmutzig-graugelb, enthült auch im Innern Narben, Marksubstanz hellgraurot. Nierenbecken fein injiziert, mikroskopische feinkörnige Trübung der Rindenepithelien. Rechte Niere gross, Kapsel leichter löslich als links, bis zweifrankstückgrosse Narben auf der Nierenoberfläche, dazwischen bis linsengrosse weisse Flecken, zum Teil gruppiert; diese prominieren und greifen streifenförmig in die Rindensubstanz. Es lässt sich aus ihnen eine eiterartige, sehr zähe Flüssigkeit entleeren. Schleimhaut des Nierenbeckens stark injiziert. Beide Nieren wiegen $270 \mathrm{~g}$. Mikroskopisch: In der Umgehung der Abszesse Fettentartung der Epithelien, einzelne Zylinder. Aus einzelnen der noch nicht reifen Abszesse lässt sich ein aus dichtgedrängten, in Verfettung begriffenen Zellen bestehendes Klümpchen herausheben. 
Das linke Ligamentum latum zeigt eine leichte, graugelbe, sulziggallertige Infiltration. Uterushöhle $10 \mathrm{~cm}$ lang, Schleimhaut graurötlich, Plazentastelle an der vorderen Wand mit schmutzigen, fetzigen, gelbgrïnen Blutgerinnseln bedeckt, diphtheritische Nekrose der Schleimhaut. Mikroskopisch finden sich noch wohlerhaltene, fettig degenerierte Zotten. Harnblase enthält etwas graugelbe, rahmige Flüssigkeit, in welcher man mikroskopisch nur Blasenepithelien findet. Darm: An der Bauhin 'schen Klappe ist die Schleimhaut schiefrig verfärbt, am Ileum alte typhöse Narben.

Leber gross, linker Lappen sehr anämisch, graurö̈lich, Gewicht 1820 g. An beiden Augäpfeln findet man streifen- und punktförmige Blutungen in der Retina.

Anatomische Diagnose: Febris puerperalis (Endometritis diphtherica, Parametritis sinistra). Nephritis interstitialis chronica et apostematosa dextra. Aorta angusta. Myocarditis parenchymatosa. Milztumor. Alte typhöse Narben im Ileum. Retinitis haemorrhagica duplex.

In diesem Falle bestand also eine monatelange Hyperemesis, die auch insofern den oben aufgestellten Forderungen entspricht, als ein bestimmtes Organleiden nicht aufzufinden war. Die Nierenbiutungen mitsamt den bei der Sektion gefundenen Hämorrhagien erklären sich wohl am einfachsten aus dem Zusammenhange mit. dem Ikterus, da sonstige Zeichen einer Nephritis, Eiweiss, Zylinder oder Oedeme nicht nachweisbar waren. In den letzten Tagen der Krankheit trat im Anschluss an die künstliche Frühgeburt Fieber auf, als dessen Ursache sich bei der Sektion eine diphtheritische Endometritis erwies. Von sonstigen Befunden ist am wichtigsten der an den Nieren erhobene, und zwar kann man hier leicht zwei ihrem Alter nach gänzlich verschiedene Veränderungen auseinander halten, einmal die in beiden Nieren vorgefundenen Narben, sodann die in der rechten gelegenen Abszesse. Ausserdem findet sich Trübung und Verfettung der Rindenkanälchen. Um mit den letzteren frischen Prozessen zu beginnen, kann wohl kein Zweifel sein, dass die Abszesse einer Infektion ihren Ursprung verdanken, sei es, dass diese auf dem Blut-oder auf dem Harnwege in die Niere gelangt war. Sie haben also mit der Hyperemesis als solcher nichts zu tun. Von besonderer Wichtigkeit sind nun aber im Hinblick auf meine früheren Erörterungen die narbigen Veränderungen beider Nieren. Dieses ist der einzige von allen Fällen, über die ich bisher berichtet habe, bei welchen sich an für die Beurteilung der Hyperemesiserkrankung wichtigen Organen fraglos ältere Veränderungen vorgefunden haben. Ich bezweifle aber mit guten Gründen, dass diese Veränderungen mit der Hyperemesis im Zusammenhange stehen. Denn es handelt șich hier um zweifellos 
596 Heinrichsdorff, Die Beziehungen der Hyperemesis gravidarum usw.

herdförmige Läsionen, denen wir sonst nirgends bei tödlich verlaufenden Fällen von Hyperemesis begegnet sind. Hierbei sind Veränderungen vielmehr immer in diffuser Weise über das Organ verbreitet. Unter diesen Umständen ist die Frage berechtigt, ob die Nierennarben nicht einer anderen Erkrankung als der vorliegenden ihro Entstehung verdanken, und da stossen wir in der Anamnese auf einen vor 9 Jahren durehgemachten Abdominaltyphus. Bei dieser Krankheit sind, obwohl auch hier die diffusen Prozesse sicher häufger sind, doch mehrfach Abszesse und Infarkte ${ }^{1}$ ) beobachtet worden, als deren Ausgang die Narben sehr wohl betrachtet werden können. Auch die schiefrige Pigmentierung der Nierennarben, die in gleicher Weise an den Residuen des typhösen Prozesses im Darme aufgefunden wurde, weisen auf deren hohes Alter und die gleiche Aetiologie mit den Darmveränderungen hin. Ich kann also nicht anerkennen, dass wir an diesem Befunde etwa einen Beweis dafür hätten, dass schon im Beginne der Hyperemesis toxische Vorgänge eine Rolle gespielt haben.

Kommen wir so hinsichtlich der Nierenveränderungen, sowohl der frischen wie der narbigen, wegen ihrer Herdform zu dem Resultat, dass sie zı der vorliegenden Hyperemesiserkrankung keine Beziehung haben, so fragt es sich anderseits, in welcher Weise wir das Auftreten des Ikterus mebrere Wochen vor dem tödlichen Ausgange aufzufassen haben. Da er mit Blutungen in die Nieren und Retira einhergeht - die Obduktion wies auch sonst noch Ekchymosen auf -, so kann er nicht als einfacher Inanitionsikterus angesehen werden. Aber auch seine im engeren Sinne hepatogene Entstehung ist völlig unbewiesen, da Leberveränderungen gänzlich vermisst wurden. Es bleibt daher nur übrig, ihn auf toxische Ursachen zurückzuführen und anzunehmen, dass lediglich eine Zerstörung der roten Blutkörperchen durch die supponierte Noxe stattgefunden hat, ohne dass bestimmte lebenswichtige Organe schwer geschädigt wurden.

Ich denke mir die Beziehungen der hier vorliegenden Veränderungen zu den im Leben beobachteten Erscheinungen mithin so: Auf Rechnung eines vor Jabren durebgemachten Typhus kommen die narbigen Prozesse in den Nieren. Die seit mehreren Monaten bestehende Hyperemesis hat einen toxischen Ikterus zur Folge, als dessen Begleiterscheinungen Nieren- und Netzhautblutungen anzu-

1) Curschmann, "Abdominaltyphus" in Nothnagel's Handbuch. 
sehen sind. In den letzten Tagen kam es im Anschluss an eine künstliche Entbindung zu einer Infektion des Endometriums und im Zusammenhang damit zu Nierenabszessen.

An diese Beobachtung schliesst sich ein weiterer Fall an, der gleichfalls in den letzten Wochen der Hyperemesis einen Ikterus dargeboten hat, ohne dass Leberveränderungen bei der Sektion aufgefunden wurden. Er ist von Kuehne aus der Ahlfeld'schen Klinik veröffentlicht worden (Monatsschr. f. Geburtsh. u. Gynäk.k. Bd. X. H. 4).

Es handelt sich um eine 17jührige I para, die am 9. XII. 1898 in die Klinik aufgenommen wurde, letzte Periode am 3. IX, bald darauf Erbrechen auch ohne Nahrungsaufnahme. Im Oktober wird das Erbrechen so bedrohlich, dass Ernährung per rectum notwendig wird.

Wegen beständig zunehmender Abmagerung -- Patientia hatte innerhalb weniger Monate 20 Pfund abgenommen - fand sie Aufnahme in die Frauenklinik. Status: innere Organe gesund, Puls 100, Temperatur 37, leichte Trübung des gekochten Urins. Vorübergehende Besserung des Erbrechens. 11. XII. ikterische Verfärbung der Haut, positive Gallenfarbstoffreaktion im Urin, auffälliger Wechsel der Stimmung. 12. XII., abends 38,6, Somnolenz, Diarrhöen, unruhiger Schlaf, Verschlechterung der Sehkraft. Ophthalmoskopisch hämorrhagische Retinitis und Papillitis, 14. XII. ausgesprochener Stupor. 16.-27. XII. Besserung insofern als das Erbrechen stark zurückgegengen ist, jedoch der Stupor anhält, ebenso die Höhe der Pulsfrequenz. 28. XII. Temperatur 38,7 , Puls 140. Patientin sehr verwirrt und anfgeregt. 29. XII. Nachts grosse Unruhe, Jaktation, Schreien, Krämpfe, Exitus.

Der Sektionsbefund dieses Falles war nun bis auf den Ikterus, der sich auch an der Leber zu erkennen gab, völlig normal. Dieses Resultat hat um so mehr Gewicht, als dem Verfasser die oben erwähnten Befunde von Lindemann und die daraus gezogenen Schlüsse über die toxische Natur der Hyperemesis bekannt waren und andererseits einem Beobachter wie Marchand, der gerade um die Erforschung der hier in Frage kommenden Leberveränderungen die grössten Verdienste hat, eine diesbezügliche Alteration des Organs sicher nicht entgangen wäre.

Trotz dieses negativen Sektionsbefundes aber ist meines Erachtens eine Intoxikation ausser Frage, das geht deutlich aus dem klinischen Berichte hervor: In den letzten $2^{1} / 2$ Wochen bestand Ikterus, Fieber, Somnolenz, Diarrhöen, hämorrhagische Retinitis, erhöhte Pulsfrequenz, schliesslich starke Unruhe, Jaktation, Koma und Krämpfe. Das Auftreten des Ikterus bezeichnet ziemlich scharf die Grenze, wo die reine, bereits monatelang bestehende Hyperemesis in das Stadium der Intoxikation übergeht. Wir 
598 Heinrichsdorff, Die Beziehungen der Hyperemesis gravidarum usw.

müssen auch hier annehmen, dass in diesem Falle toxische Stoffe nicht, wie meist, auf ein bestimmtes Organ, sei es Leber oder Niere ihre deletäre Einwirkung ausgeübt haben, sondern dass durch eine Schädigung des Blutes Ikterus erzengt wurde und das ganze Heer der übrigen Symptome. In diesem Punkte trifft dieser Fall also mit dem vorigen zusammen.

Es ist von Interesse, dass der Ikterus bei der Hyperemesis von ganz verschiedener Genese sein kann: er kann einmal durch die Inanition an sich bedingt sein. Dieser Ikterus ex inanitione wird durch eine Stagnation der für die Verdaung nicht benötigten Galle erklärt, ist immer nur sehr leichten Grades und ohne die sonstigen Begleiterscheinungen schwererer Formen der Gelbsucht. In Lang's und meinem Falle bin ich aus diesen Gründen geneigt, für die Zeit vor dem Eintritt der schweren Erscheinungen einen so gearteten Ikterus anzunehmen. Die zweite und wichtigste Ursache für das Auftreten des Ikterus im Krankheitsbilde der Hyperemesis ist eine Erkrankung des Leberparenchyms, wie wir mehrfach gesehen haben. Dieser Ikterus tritt entsprechend dem späten Ausbruch der Lebererkrankung immer erst wenige Tage vor dem Tode auf, zugleich oder im Anschluss an schwere Allgemeinerscheinungen. Mit einer dritten Art des Ikterus haben wir es nun in den beiden letzt beschriebenen Fällen zu tun. Auch er geht mit Symptomen einher, die, wie die Blutungen, auf eine toxische Aetiologie hinweisen, wird aber während einer längeren Zeitdauer beobachtet als der soeben genannte, offenbar weil, wie das negative Resultat der Obduktion zeigt, eine schwere Schädigung lebenswichtiger Organe nicht so unmittelbar eintritt.

Dieser Ikterus ist in der Pathologie der Schwangerschaft nicht unbekannt. Ich habe bereits an anderer Stelle1) darauf hingewiesen, dass Brauer über Fälle von toxischem Ikterus berichtet hat, die er gleichfalls auf einen Blutkörperchenzerfall zurückführt. In dem einen bestand Hämoglobinurie, in dem anderen nicht. Er rechnet aber auch für den zweiten Fall mit der Möglichkeit einer Hämoglobinämie, einer Möglichkeit, die auch für unsere Fäille vorliegt; diese wird um so wahrscheinlicher gemacht, als Leberveränderungen, die daneben noch als Quelle für den Ikterus in Betracht kämen, durch die Sektion ausgeschlossen werden konnten. Letzteres war bei Brauer nicht möglich, da die Pat. genasen. -

1) Die anat. Leberveränderungen in der Sohwangerschaft. I. c. S. 654. 
Ein völlig negatives Sektionsergebnis lieferte ferner ein Fall der Leipziger Klinik, der bisher nicht veröffentlicht worden ist und für dessen Ueberlassung ich den Herren Professoren Strümpell und Marchand zu Dank verpflichtet bin.

Aufnahme am 7. I. 1904. Seit 4 Wochen bestehen Magenschmerzen und Erbrechen, letzte Periode vor 7 Wochen. Status: Zunge belegt, Foetor ex ore, innere Organe gesund, Magen gegen Druok empfindlich. Leberdämptung schneidet in der Mammillarlinie mit dem Rippenbogen ab. 17. I. Patientin bricht immer frühmorgens grïnlich gefärbte Flüssigkeit aus. Nährklystiere. Gravidität wird bestritten. 1. II. Erbrechen besteht fort, Magengegend nicht mehr schmerzhaft, dagegen Schmerzen unterhalb des Nabels. 15. II. Heute früh und gestern Abend starke Blutungen aus den Genitalien. 16. II. Wieder starke Blutung, da der Uterus vergrössert ist, wird Patientin auf die Frauenklinik verlegt. Im Urin wurden mehrfach Spuren Eiweiss nachgewiesen, Temperatur stets normal, dagegen war der Puls in den letzten Wochen in die Höhe gegangen und betrug in den letaten Tagen 110 bis 120 in der Minute.

In der Frauenklinik hörten die Blutungen auf. Es entwickelten sich aber allmählich Somnolenz, Mattigkeit, Kopfschmerzen und Schmerzen in den Beinen. Sie wird daher am 20. II. auf die innere Klinik mit der Diagnose "Meningitis" zurückverlegt. Patientin ist im Koma, zeigt "grosse Atmung". Auf Anrufen keine Reaktion, Pupillen weit, reagieren prompt, Zuckungen in dem rechten Fazialis und im rechten Arm, sichere Zeichen von Meningitis fehlen, Herzaktion sehr beschleunigt, ca. 160, beginnendes Lungenödem, Kochsalzinfusion, Kampfer, der katheterisierte Urin zeigt kein Eiweiss. 21. II. Exitus.

Sektionsbefund (Dr. Versé). Kein Ikterus. Pia mater stark ödematös, sonst o. B. Herz klein, rechter Ventrikel schwach, von dunkelbrauner Farbe. Lungen: Beide Unterlappen stark ödematös. Magen: Schleimhaut stark geschwollen, besonders gegen den Pylorus zu, starke längs verlaufende Faltenbildungen, keine erhebliche Gefässinjektion. Leber von gewöhnlicher Grösse und Konsistenz, auf dem Durchschnitt hat das Parenchym eine braunrote Farbe, Läppchenzeichnung deutlich. Nieren: Kapsel leicht abziehbar, Parenchym blutreich. Keine besonderen pathologischen Veränderungen. Uterus kindskopfgross, zwischen Uteruswand und Plazenta findet sich ein grosser Bluterguss.

Es handelt sich somit um eine Hyperemesis gravidarum, die nach 10 Wochen langer Dauer zum Tode führte, ohne dass man durch die Sektion eine Erklärung für den Tod finden konnte. Das. retroplazentare Hämatom kann bei dem frähen Stadium der Gravidität. natürlich als Todesursache nicht in Frage kommen. Der Kliniker sah sich genötigt, Tod durch Entkräftung anzunehmen. Eine Intoxikation ist jedenfalls weder aus dem klinischen noch aus dem pathologisch-anatomischen Bilde mit einiger Sicherheit herzuleiten.

Der Fall bietet eine wichtige Illustration zu der Frage, obPatienten mit Hyperemesis lediglich an dem Erbrechen zugrunde 
gehen können. Bei dem Streit über die Genese dieser Erkrankung ${ }^{1}$ ) wurde den Anhängern der nervösen Theorie entgegengehalten, dass sie die Todesfälle nicht erklären können. Ich habe im Einklang mit Winter gezeigt, dass man die durch soviel Beispiele bewiesene nervöse Theorie aufrecht erbalten könne und doch den Tod in den meisten Fällen als durch toxische Ursachen bedingt auffassen müsse. Hier aber liegt eine Beobachtung vor, wo auch die Anhänger der toxischen Theorie ihre Lehre durch nichts beweisen können. Habe ich im Vorhergehenden betont, dass wir keine stichbaltigen Beweise für den toxischen Ursprung der Erkrankung haben, so muss man für diesen Fall sogar einräumen, dass wir auch keinen Beweis für die toxische Ursache des Todes haben. Ich möchte mich daher denen (Krönig) anschliessen, die auch schon auf dem Leipziger Kongress ihre Stimme dafür erhoben haben, dass es denkbar sei, dass durch das Erbrechen herabgekommene Personen - auch, wenn dieses nur nervös-bysterischer Natur sei - daran zugrunde gehen. Auch Binswanger ${ }^{2}$ ) schuldigt in einem Falle von hysterischem Erbrechen - ohne Gravidität -die chronische Unterernährung als Todesursache an und erwähnt einen Parallelfall von Guyot mit letalem Ausgang; bei welchem das Erbrechen 83 Tage gedauert hatte. Auch Williams gibt diese Möglichkeit zu. Welche Faktoren der Inanition so deletär wirken - der Mangel an Nährstoffen, die Anhäufung von Azetonkörpern, oder der Wasserverlust - bleibe dahingestellt.

Diese Beobachtung hat für die uns hier beschäftigende Frage keine geringe Bedeutung, da sie sowohl klinisch wie anatomisch sichere Zeichen einer Intoxikation vermissen lässt. Es ist ein ganz reiner Fall von Hyperemesis und zeigt, dass diese an und für sich mit einer Intoxikation nichts zu tun hat; er beweist ferner, dass es eine pathologische Anatomie der Hyperemesis nicht gibt, und das entpricht völlig dem klinischen Bilde, indem es unmöglich ist, eine bestimmte Organerkrankung nachzuweisen. Alle bei dieser Affektion erhobenen Sektionsbefunde hängen mit Komplikationen zusammen. Als solche kommen auch ganz abseits gelegene Erkrankungen vor. So wurde in der hiesigen medizinischen Klinik folgender Fall beobachtet, dessen Krankengeschichte mir Herr Prof. Bittorf freundlichst zur Verfügung stellte:

1) Gynäkologen-Kongress zu Leipzig. 1900.

2) "Hysterie" in Nothnagel's Handbuch. 
24jährige Ipara. 24. I. 1908 Aufnahme in die medizinische Klinik, letzte Nienses Mitte Dezember. Vor 6 Tagen starkes Erbrechen nach dem Essen, nach heftigem Erbrechen auch Magen- und Kopfschmerzen. Das Erbrechen wiederholte sich an den folgenden Tagen etwa 4- bis 5 mal täglich. Status: Reduzierter Erährungszustand. Zunge belegt, Magen etwas druckempfindlich. Innere Organe o. B. Schwangerschaft im 3. oder 4. Monat. 13. II. Erbrechen hat bis jetzt fortgedauert, Patientin nimmt stetig an Körpergewicht ąb. 17. II. Puls sehr frequent, durchschnittlich 120, bisweilen bis 160 in der Minute ansteigend. 20. II. Fortdauerndes Erbrechen, Puls frequent und klein. Beim Kochen des Urins leichte Trübung. 24. II. Das Körpergewicht nahm in den letzten Wochen um je $2 \mathrm{~kg}$ ab. Haut sehr trocken. Puls ca. 140, aber wechselnd in bezug auf Frequenz und Höhe, Herzklopfen, starker Durst. 25. II. Bis dahin normale Temperatur steigt leicht an, Patientin klagt über Seitenstechen, fühlt sich sehr schwach. 26. II. In der Nacht war Patientin sehr unruhig, verlässt fortwährend das Bett, klagt über stärkere Schmerzen, Puls klein, bis 160. 27. II. Klagen über Seitenstechen halten an, an den Lungen kein Befund, Temp. $40^{\circ}$; mittags wird sie benommen, keine Lähmungen, abends reagiert sie nicht mehr auf Anruf, Puls ist sehr klein, nachts erfolgte Exitus.

Bei der Sektion findet man im linken Unterlappen eine Bronchopneumonie, ausserdem Blutungen im Magen und Darm, Fettleber; keinen Ikterus.

Als Todesursache muss man hiernach die Lungenentzündung ansehen; ob daneben auch eine Intoxikation vorgelegen hat, steht dahin. -

Ordnen wir der besseren Uebersicht wegen die hier besprochenen Fälle nach Todesursachen, so finden wir folgendes:

$$
\text { Fälle Todesursache }
$$

Hirschberg. . . . Akute Leberdegeneration mit Atrophie,

\section{Lang}

Zaborsky

Williams

Heinrichsdorff

Solowjew-Lindemann

Winter-Hofbauer.

Champetier de Ribes und

Bouffe de St. Blaise

Erismann I.

Erismann II.

Kuehne

Leipziger Klinik.

Breslauer Klinik.

$\begin{array}{cccc}n & n & n & n \\ n & n & n & n \\ n & n & n & n \\ n & n & n & n \\ n & n & n & n\end{array}$

Eklampsie,

Akute hämorrhagische Nephritis,

Toxischer Ikterus,

Hyperemesis,

Bronchopneumonie.

Hieraus ergibt sich, dass weitaus die meisten der tödlich endenden Fälle von Hyperemesis durch Intoxikationskrankheiten 
zugrunde gehen. Die grösste Rolle unter diesen spielt wiederum die meist zur Atrophie führende parenchymatöse Leberdegeneration. Es muss auffallen, dass diese einen so breiten Raum unter den Todesursachen einnimmt, und nicht vielmehr die Eklampsie, obwohl die letztere unzweifelhaft in der Schwangerschaft viel häufiger ist als die erstere. Ich glaube den Grund darin sehen zu müssen, dass jene diffuse Form der Lebererkrankung, als deren stärkster Ausdruck die akute gelbe Leberatrophie gelten darf, in einer früheren Periode der Schwangerschaft aufzutreten pflegt als die Eklampsie, die in der Regel erst gegen das Ende der Gravidität angetroffen wird. Aber ebenso wie diese Regel im allgemeinen nicht ohne Ausnahme ist, so gilt dieses auch für den speziellen Fall der Hyperemesis, wie die Beobachtung von Champetier de Ribes und Bouffe de St. Blaise zeigt. Tch meine also: Die grössere Häufigkeit der diffusen Lebererkrankung gegenüber der herdförmigen bei der Eklampsie erklärt sich aus dem Auftreten der Hyperemesis in früheren Monaten der Gravidität.

Nehmen wir noch die übrigen Affektionen, an denen Hyperemesiskranke sterben können - toxischer Ikterus, Nierenentzündung - hinzu, so haben wir alle diejenigen Intoxikationskrankheiten beisammen, die auch ohne dass eine Hyperemesis vorauszugeben braucht, das Leben der Schwangersn bedrohen. Man kann also sagen, dass alle die terminal bei der Hyperemesis auftretenden Toxikosen ein hyperemesisfreies Vorbild in der Pathologie der Schwangerschaft haben. Nichts zeigt klarer wie diese Tatsache, dass die Toxikosen mit der Hyperemesis von Hause aus nichts zu tun haben, vielmehr eine völlig selbständige Krankheit darstellen, die sich erst zur Hyperemesis hinzuaddiert.

Damit wird die Richtigkeit der Winter'schen Theorie, die von ihrem Autor wesentlich auf Grund klinischer Beobachtungen aufgestellt wurde, durch das Resultat der anatomischen Untersuchungen bewiesen. Durch die Sektionsbefunde wird also nicht, wie ich früher glaubte, der toxische Ursprung, sondern lediglich der toxische Ausgang der tötlich verlaufenden Hyperemesisfälle dargethan.

Ich habe nun noch auf einige Krankheitsbilder einzugehen, die wegen einer oberflächlichen Aehnlichkeit mit der Hyperemesis mit dieser identifziert worden sind und so zu irrigen Schlussfolgerungen über das Wesen dieser Erkrankung geführt haben. 
Nicht alles, was während der Schwangersehaft klinisch ais Erbrechen in die Erscheinung tritt, ist eine Hyperemesis. Das gilt nicht nur von solchen Affektionen, die bereits unter einem bestimmten Krankheitsbegriff eingeordnet sind, und deren Abgrenzung gegen die Hyperemesis wir bereits oben vorgenommen haben, sondern auch von solchen Fällen, die erst in der letzten Zeit gebührende Beachtung gefunden baben, und über deren Auffassung daher noch keine Einigung erzielt ist.

Schon bei Besprechung der obigen Fälle habe ich auf die Beobachtungen von $\mathrm{Ewing}$ und Stone hingewiesen, die ich wegen ihres akuten Verlaufes nicht als Hyperemesiserkrankung gelten lassen konnte. Wie haben wir nun diese Krankheitsformen aufzufassen? Schon die klinischen Befunde - Ikterus im Falle von Ewing, Leuzin und Tyrosin im Harne bei Stone - weisen in die Richtung der akuten gelben Leberatrophie, und die anatomischen Merkmale lassen sich nötigenfalls mit dieser Annahme auch vereinigen. Bei Stone war eine deutliche Verkleinerung der Leber vorhanden, bei Ewing war dieselbe kaum angedeutet; histologisch waren im ersten Falle schon Zerstörung des Leberparenchyms nachweisbar, allerdings waren die Läppchen nicht wie gewöhnlich bei der akuten gelben Arrophie total zerstört, sondern lediglich in ihren peripheren Schichten, während die zentralen völlig unversehrt waren. In dieser Lokalisation liegt eine wesentliche Differenz gegenüber den früher besprochenen Leberveränderungen, die mit Ausnahme des Winter-Hofbauer'schen Falles alle in den Zentren der Läppchen Zerfallserscheinungen aufwiesen. Im Falle Ewing's war eine diffuse Erkrankung des Gesamtparenchyms vorhanden ohne, dass eine bestimmte Lokalisation erkennbar gewesen wäre.

Was nun die Stellung dieser Erkrankungen anlangt, so könnte man sie, wie schon angedeutet, zur akuten Atrophie rechnen. Sie stellen aber offenbar nur unentwickelte Formen dieser Krankheit dar, da beträchtliche Anteile des Leberparenchyms erhalten sein können und die Atrophie nicht vorhanden zu sein braucht. Man erinnere sich daran, dass ich auch bei den oben beschribenen 5 Fälle von Hyperemesis, die ihren Ausgang in "akute Atrophie“ genommen haben, auf ein ganz ähnliches Verhalten eines Teils der hierbei gefundenen Lebern hingewiesen habe, und dass weiterhin in 2 anderen Fällen von Hyperemesis degenerative Leberveränderungen ohne Atrophie aufgefunden wurden. Die Zahl dieser 
604 Heinrichsdorff, Die Beziehungen der Hyperemesis gravidarum usw.

Fälle von Leberentartung lässt sich nun vermehren durch eine weitere schon oben angeführte Beobachtung von Ewing (dessen Fall II) ${ }^{1}$ ) und 2 Fälle von Schickele ${ }^{2}$, die ich hier noch anführen möchte.

In der einen Beobachtung dieses Verfassers bestanden Kopfschmerzen, Bewusstlosigkeit, Zuckungen im Gesicht und Armen, Nackenstarre, Kernig'sches Symptom, Temperatur bis 39, im Urin Eiweiss und Zylinder. Es wurde eine tuberkulöse Meningitis angenommen. Bei der Sektion sind die Meningen völlig normal, die Leber ist auffallend schlaff, nicht vergrössert, das Parenchym auf dem Durchschnitt von blassrötlichgrauer, zum Teil gelber Farbe, Azinuszeichnung ist vorhanden. Die mikroskopische Untersuchung weist eine ausgedehnte Anhäufung von Fett in den Leberläppchen nach, sodass nur die unmittelbar an den Verzweigungen der Glisson'schen Kapsel liegenden Leberzellen davon freibleiben. Diese sind zum grössten Teil noch erhalten und zeigen höchstens eine geringe Trübung, alle anderen, also der bei weitem überwiegende Teil des Azinus zeigen deutliche Zeichen von Degeneration, Schrumpfung der Zelle und Kernzerfall, in anderen fehlt der Kern gänzlich, die Zellkonturen sind unregelmässig, sodass einzelne Partien des Lebergewebes gänzlich zerfallen sind und nur noch Reste von Elementen aufweisen.

Der zweite Fall von Schickele wurde im 3. Monat der 2. Gravidität beobachtet, Patientin war nur zwei Tage krank. Beim Eintritt in die Klinik zeigt sie starke Zyanose, kleinen frequenten Puls, Temperatur 36,3; Urin war stark bluthaltig, auch im ausgeheberten Mageninhalt findet sich Blut; zahlreiche Petechien in der Haut. Bei der Sektion ist die Leber vergrössert, besonders der rechte Lappen 26:21:10, auffallend gelb, auch der Durchschnitt ist von zitronengelber Farbe, nur die Zentren der Azini heben sich durch ihre braune Farbe stark ab. Nieren sind gross, besonders die rechte $13: 6^{1} / 2: 4$. In der Niere und ihrer Umgebung Blutungen, die sich fast in allen Organen: Haut, Netz, Mesenterium, Pleura, Peritoneum, retroperitonealem Raum, Magen und Darm vorfinden. Der letzte Befund ist allerdings so auffallend und sonst nirgends beobachtet, dass ich Zweifel an der gravidären

1) S. 568 .

2) Beiträge zur Physiologie und Pathologie der Schwangerschaft. Dieses Arehiv. Bd. 92. (Fall V und VII dieses Autors:) 
A etiologie dieser Intoxikation bereits ausgesprochen habe. Immerhin aber ist die Berechtigung dieser Auffassung, zumal unsere Einsicht in diese Dinge noch sehr in den ersten Anfängen ist, nicht auszuschliessen. Jedenfalls handelt es sich auch in diesen Fällen um eine diffuse degenerative Lebererkrankung mit Verfettung und Zerfall der Elemente, offenbar infolge toxischer Einflüsse.

Aus dem Gesagten geht hervor, dass man alle diese Erkrankungen, die durch ihren akuten Verlauf und die Degeneration des Leberparenchyms ausgezeichnet sind, zusammenfassen darf, und dass sie eine besondere Form von Schwangerschaftsintoxikation darstellen. Sie treten ebenso wie die übrigen, sowohl allein, als auch im Anschluss an eine Hyperemesis auf und spielen offenbar in der Pathologie der Schwangerschaft eine bemerkenswerte Rolle. Sie als akute Formen der Hyperemesis aufzufassen, wie Einige gewollt haben, verbietet sich, abgesehen von anderen bereits oben ausführlich erörterten Gründen, schon darum, weil die letzten hier beigebrachten Beobachtungen das Erbrechen völlig vermissen lassen.

Ebenso kann man diese Fälle nicht gut als akute Leberatrophie gelten lassen. Ich schlage daher vor, sie als toxische Leberentartung zu bezeichnen.

Die. Beziehungen der 3 hier untersuchten und unterschiedenen Affektionen lassen sich in folgender Uebersicht ausdrücken:

\begin{tabular}{|c|c|c|}
\hline Hyper & $\begin{array}{c}\text { Toxische } \\
\text { Leberentartung }\end{array}$ & Gelbe Leberatrophie \\
\hline Klin.: Chron. Verlauf. & Klin.: Akuter Verlauf. & $\begin{array}{l}\text { Klin.: Akuter i. chro- } \\
\text { nischer Verlauf. }\end{array}$ \\
\hline Sektionsbefund: & Sektionsbefund: & Sektionsbefund: \\
\hline $\begin{array}{l}\text { Keine Organveränderun- } \\
\text { gen. }\end{array}$ & $\begin{array}{l}\text { Leberdegeneration mit ver- } \\
\text { grösserter, normalgrosser } \\
\text { und verkleinerter Leber. } \\
\text { Histolog.: Meist nur par- } \\
\text { tielle Zerstörung des } \\
\text { Parenchyms. }\end{array}$ & $\begin{array}{l}\text { Leberatrophie. Histolog.: } \\
\text { Totale Zerstörung des } \\
\text { Parenchyms. Bei chro- } \\
\text { nischem Verlauf: Re- } \\
\text { generationserscheinun- } \\
\text { gen. }\end{array}$ \\
\hline $\begin{array}{l}\text { Tod: } \\
\text { 1. Dureh Inanition. } \\
\text { 2. Durch Intoxikationen. } \\
\text { 3. Dureh interkurrente } \\
\text { Erkrankung. }\end{array}$ & $\begin{array}{c}\text { Tod: } \\
\text { Durch die Intoxikation. }\end{array}$ & $\begin{array}{l}\text { Tod: } \\
\text { Durch die Schwere der } \\
\text { Lebererkrankung. }\end{array}$ \\
\hline
\end{tabular}

Es möge mir gestattet sein, aus den vorliegenden Untersuchungen auch für die geburtshilfliche Praxis einige Schlüsse za ziehen. 
Was zunächst die zuletzt beschriebene Schwangerschaftsintoxikation anlangt, die also die Individuen bei völliger Gesundheit überrascht, so zeigt der akute, in manchen Fällen sogar perakute Verlauf der Krankheit die Unmöglichkeit, hier Hilfe zu bringen. Ehe man noch die Diagnose zu stellen vermag, ist der Krankheitszustand bereits ein hoffnungloser. Fast ebenso infaust ist die Prognose der akuten gelben Leberatrophie, obwohl hier bei dem typischen Verlauf eine rechtzeitige Diagnose schon eher ermöglicht wird, und in der Tat ist durch Schnellentbindung der eine oder der andere Fall auch gerettet worden.

Bei der Hyperemesis liegen die Dinge so: Im Stadium der reinen Hyperemesis wird man nicht entbinden, da die meisten Fälle auch ohne dies einen günstigen Verlauf nehmen; ist aber einmal die Intoxikation da und als solche erkannt, so ist es in der Regel schon zu spät, eben weil diese so rasch tödlich verläuft. Es scheint auch, dass in diesem Stadium der künstliche Abort ein so schwerer Eingriff ist, dass er das tödliche Ende nur beschleunigt. Es hat daher an Bemühungen nicht gefehlt, Indikationen aufzustellen, welche die Entbindung bereits zu einer aussichtsvolleren Zeit vorzunehmen gestatten. Es ist besonders von französischen Autoren (Pinard) auf das Symptom der hohen, namentlich im Verbältnis zur Temperaturkurve erhöhten Pulsfrequenz aufmerksam gemacht worden. In der Tat ist es häufig bei den hier besprochenen Fällen beobachtet, aber keineswegs immer, und es fragt sich noch, ob es nicht auch bei günstig verlaufenden Fällen gefunden wird. Ferner ist der Ikterus so ein alarmierendes Zeichen, leider tritt er aber meist erst sehr spät in die Erscheinung, dann nämlich, wenn er einer deletären Lebererkrankung entspringt. In manchen Fällen aber ist er in der Tat wochenlang vor dem tödlichen Ende beobachtet worden, aber selbst hier ist die Indikation zur künstlichen Frühgeburt noch nicht ohne weiteres gegeben; denn der Ikterus ist kein eindeutiges Symptom. So kann er lediglich durch Inanition bedingt sein; das wird man annehmen müssen, wenn er nur in ganz leichter Form und ohne andere Intoxikationserscheinungen (Nieren-, Netzhautblutungen!) auftritt. Ueberdies fehlt auch hier der Nachweis, dass er nur bei tödlich endenden Fällen angetroffen wird. Die Eiweissausscheidung schliesslich ist weiterhin in Betracht zu ziehen; sie ist am unsichersten; meist handelt es sich nur um Spuren, die auch sonst häufig in der Gravidität gefunden werden, oft fehlt sie überhaupt ganz. 
Alle diese Symptome - zusammen oder einzeln - können, wenn sie zu einer Zeit auftreten, wo schwere Allgemeinerscheinungen noch nicht vorhanden sind, die Indikation zur künstlichen. Frühgeburt abgeben mit Aussicht auf Erfolg. In manchen Fällen aber fehlen solche Warnungszeichen gänzlich. Wenn man unsere Fälle nach dieser Richtung hin zusammenstellt, ergibt sich folgendes:

\begin{tabular}{|c|c|c|c|}
\hline $\begin{array}{c}\text { Fälle } \\
\text { von Hyperemesis }\end{array}$ & $\begin{array}{l}\text { Mebrere Woel } \\
\text { Hobe } \\
\left.\text { Pulsfrequenz }{ }^{1}\right)\end{array}$ & $\begin{array}{c}\text { en vor dem Tode } \\
\text { Ikterus }\end{array}$ & $\begin{array}{l}\text { auftretende } \\
\text { Eiweiss- } \\
\text { ausscheidung }\end{array}$ \\
\hline 1. Hirsehberg ...... & 一 & - & - \\
\hline 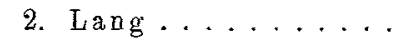 & + & $+($ Inanition? $)$ & $?$ \\
\hline 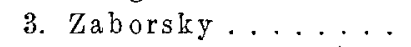 & - & - & - \\
\hline 4. Williams .......... & - & 一 & - \\
\hline 5. Heinrichsdorff. & $+2)$ & $+($ Inanition? $)$ & + \\
\hline 6. Solowjew-Lindemann & + & - & + \\
\hline 7. Winter-Hofbauer... & \multicolumn{3}{|c|}{$\begin{array}{l}\text { Keine detaillierten Angaben, jedenfalls keine } \\
\text { positiven Befunde }\end{array}$} \\
\hline 8. Erismann I. & + & - & $\left.+^{3}\right)$ \\
\hline$" \quad I I . \ldots$. & + & $+(\operatorname{toxiseh})$ & - \\
\hline 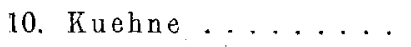 & + & $+($ toxisch $)$ & + \\
\hline 11. Leipziger Klinik . . . . . & + & - & - \\
\hline 12. Breslauer Klinik .... & + & - & + \\
\hline $\begin{array}{l}\text { 1) Pulszahlen unter } 100 \\
\text { 2) Tachykardie soll hier } \\
\text { 3) Nur in diesem Falle }\end{array}$ & erden nicht 1 & $\begin{array}{l}\text { u gerechne } \\
\text { n haben. } \\
\text { hritis, sor }\end{array}$ & \\
\hline
\end{tabular}

Híernach wäre die hohe Pulsfrequenz noch am konstantesten; um sie aber als Indikation für die Vornahme der künstlichen Frühgeburt zu verwerten, müsste man erst wissen, ob sie in günstig auslaufenden Fällen fehlt. Ueberdies wird ja auch dieses Zeichen in einzelnen Beobachtungen vermisst.

Vielleicht gelingt es nun, noch eine andere Eigentümlichkeit für die frühzeitige Erkennung der drohenden Gefahr nutzbar zu machen. Nach Untersuchungen, die Williams (l.c.) und Ewing (l.c.) angestellt haben, legen diese Autoren einen besonderen Wert auf. die Erhöhung des Ammoniakgehalts des Urins und beurteilen danach die toxische Natur des Falles. Eine eingehende Nachprüfung ihrer Ergebnisse fehlt bisher in der deutschen Literatur, so dass über diesen Punkt noch keine völlige Gewissheit herrscht; sie herbeizuführen, ist aber eine dringende Notwendigkeit. 
608 Heinrichsdorff, Die Beziehungen der Hyperemesis gravidarum usw.

\section{Zusammenfassung.}

1. Die Hyperemesis ist eine typische Krankheit der ersten Hälfte der Gravidität, die sich über Wochen und Monate erstreckt und ' $\mathrm{zu}$ hochgradigem Gewichtsverlust führt, ohne dass eine Organerkrankung als Ursache dieses Zustandes aufzufinden ist. Sie geht. meist in Heilung aus.

2. In sehr seltenen Fällen jedoch tritt auch bei reiner Hyperemesis der Tod ein, und der Sektionsbefund bietet dann keine positiven Ergebnisse.

3. Es gibt in der Gravidität Intoxikationen, die wir unter den Begriff "Eklampsie", "akute gelbe Leberatrophie" seit langem kennen. Hierzu sind neuerdings noch weitere Intoxikationszustände getreten, die ein so scharf umschriebenes und einheitliches Krankheits- und Sektionsbild, wie die soeben genannten vermissen lassen, und sich anatomisch meist als Parenchymdegeneration der Leber, seltener als akute hämorrhagische Nephritis oder auch als toxischer Ikterus darstellen.

4. Diese Intoxikationen entwickeln sich nun entweder aus voller Gesundheit heraus oder auf der Basis einer Hyperemesis. Demgemäss sieht man auch im klinischen Bilde.der letzteren häufigmehr oder minder plötzlich eine Verschlimmerung und Veränderung des Krankheitsbildes hervortreten, die bisher als drittes Stadium der Hyperemesiskrankheit aufgefasst wurde.

5. Die Sektionsbefunde bei der Hyperemesis können nicht als anatomischer Ausdruck einer dieser Erkrankung etwa zugrunde liegenden Intoxikation betrachtet werden. Denn erstens besteht ein deutliches Missverhältnis zwischen der langen Dauer der Hyperemesis und der Frische der Organveränderungen. Zweitens aber werden ganz gleiche Sektionsbefunde bei akut verlaufenden Schwanschaftsintoxikationen beobachtet, bei denen gar keine Hyperemesis bestanden hat.

6. Die Hyperemesis kommt nicht von einer Intoxikation her, sondern geht in eine Intoxikation über. So erklärt sich in der Mehrzahl der Fälle der tötliche Ausgang der Krankheit. 